\title{
Sipjeondaebo-tang Alleviates Oxidative Stress-Mediated Liver Injury through Activation of the CaMKK2-AMPK Signaling Pathway
}

\author{
Sang Mi Park $\mathbb{D},{ }^{1}$ Sung Woo Kim $\mathbb{D}^{2},{ }^{2}$ Eun Hye Jung, ${ }^{1}$ Hae Li Ko, ${ }^{1}$ Chae Kwang Im, ${ }^{2}$ \\ Jong Rok Lee, ${ }^{3}$ Sung Hui Byun, ${ }^{1}$ Sae Kwang Ku $\mathbb{D}^{\mathbb{D}},{ }^{4}$ Sang Chan Kim ${ }^{(\mathbb{D},},{ }^{1}$ Chung A Park, ${ }^{5}$ \\ Kwang Joong Kim $\left(\mathbb{D},{ }^{2} \text { and Il Je Cho }{ }^{1}\right)^{1}$ \\ ${ }^{1}$ Department of Herbal Formulation, College of Korean Medicine, Daegu Haany University, Gyeongsan 38610, Republic of Korea \\ ${ }^{2}$ Department of Physiology, College of Korean Medicine, Daegu Haany University, Gyeongsan 38610, Republic of Korea \\ ${ }^{3}$ Department of Pharmaceutical Engineering, College of Bio-Technology, Daegu Haany University, Gyeongsan 38610, Republic of Korea \\ ${ }^{4}$ Department of Histology and Anatomy, College of Korean Medicine, Daegu Haany University, Gyeongsan 38610, Republic of Korea \\ ${ }^{5}$ Department of Internal Medicine, College of Korean Medicine, Daegu Haany University, Gyeongsan 38610, Republic of Korea
}

Correspondence should be addressed to Kwang Joong Kim; kwangj@dhu.ac.kr and Il Je Cho; skek023@dhu.ac.kr

Received 13 July 2018; Revised 17 September 2018; Accepted 30 September 2018; Published 6 November 2018

Academic Editor: Shao-Hsuan Kao

Copyright (c) 2018 Sang Mi Park et al. This is an open access article distributed under the Creative Commons Attribution License, which permits unrestricted use, distribution, and reproduction in any medium, provided the original work is properly cited.

\begin{abstract}
Sipjeondaebo-tang (SDT) is used frequently as a herbal prescription to treat deficiency syndromes in traditional Korean medicine. We investigated the hepatoprotective effects of SDT against oxidative stress and attempted to clarify the underlying molecular mechanisms. SDT pretreatment reduced arachidonic acid (AA) plus iron-mediated cytotoxicity in a concentrationdependent manner and prevented changes in apoptosis-related protein expression. In addition, SDT pretreatment significantly reduced glutathione depletion, hydrogen peroxide production, and mitochondrial dysfunction via treatment with AA plus iron. SDT increased the phosphorylation of AMP-activated protein kinase (AMPK) in accordance with the phosphorylation of $\mathrm{Ca}^{2+} /$ calmodulin-dependent protein kinase kinase 2 (CaMKK2). Experiments using an AMPK chemical inhibitor (Compound C) or CaMKK2 chemical inhibitor (STO-609) suggested that the CaMKK2-AMPK signaling pathway contributes to SDT-mediated protection of mitochondria and cells. Moreover, administration of SDT for 4 consecutive days to mice significantly reduced the alanine aminotransferase and aspartate aminotransferase activities induced by carbon tetrachloride, and the numbers of degenerated hepatocytes, infiltrated inflammatory cells, nitrotyrosine-positive cells, and 4-hydroxynonenal-positive cells in liver tissue. Therefore, SDT protects hepatocytes from oxidative stress via CaMKK2-dependent AMPK activation and has the therapeutic potential to prevent or treat oxidative stress-related liver injury.
\end{abstract}

\section{Introduction}

Oxidative stress, caused by an imbalance between reactive oxygen species (ROS) and the antioxidant defense system, plays an essential role in the pathogenesis of various types of liver disease, including hepatitis, steatosis, and fibrosis [1]. Excess ROS generation, i.e., that beyond the adaptive capacity, provokes oxidation of biomolecules in hepatocytes, reduces their cellular function, and promotes cell death. In particular, ROS modifies lipids in the plasma membrane and releases arachidonic acid (AA), a proinflammatory $\omega-6$ polyunsaturated fatty acid [2]. AA induces mitochondriadependent apoptosis of hepatocytes [3]. Moreover, in the presence of iron, AA promotes ROS generation in cells and mitochondria, depletes reduced glutathione (GSH), induces mitochondrial membrane leakage, and accelerates apoptosis of hepatocytes $[3,4]$.

To cope with oxidative stress, cells regulate the activity of diverse signaling pathways. Among these, AMPactivated protein kinase (AMPK) is an evolutionarily conserved serine/threonine kinase and is regarded as a redoxsensitive master regulator that protects cells from oxidative 
and metabolic stress $[5,6]$. AMPK is a heterotrimeric protein composed of a catalytic subunit ( $\alpha$ subunit) and two regulatory subunits ( $\beta$ and $\gamma$ subunits). Although AMPK isoforms are differentially expressed in different tissues, AMPK activity is regulated by phosphorylation of the catalytic subunit and via allosteric binding of adenosine phosphates to the regulatory subunit [5]. In the liver, AMPK activation halts anabolic processes (e.g., fatty acid, carbohydrate, and protein synthesis) and promotes catabolic processes (e.g., fatty acid oxidation and glucose uptake). Interestingly, AMPK inhibits glycogen synthase- $3 \beta$ (GSK-3 $\beta$-) mediated mitochondrial impairment, facilitates mitochondrial biogenesis via the peroxisome proliferatoractivated receptor $\gamma$ coactivator- $1 \alpha$, and activates autophagy to remove damaged macromolecules [6]. Because the mitochondrion is an essential subcellular organelle for accelerating oxidative stress, maintaining mitochondrial integrity and homeostasis via AMPK provides a prosurvival signal against oxidative stress. Several medicinal herbs and isolated natural products that protect against oxidative stress via AMPK activation have been identified [4, 7$10]$.

In traditional Korean, Chinese, and Japanese medicine, no single herb is applied; instead, prescriptions comprising multiple medicinal herbs are frequently used to treat diverse diseases. According to the "king-minister-assistantambassador" theory (Kun-Shin-Jua-Sa in Korean; Jun-ChenZuo-Shi in Chinese) in traditional medicine, use of a combination of medicinal herbs can enhance the pharmacological activities of the major acting herbs (i.e., "king drugs"), helps distribute king drugs to the target organ(s), and reduces unwanted side effects of king drugs [11]. Due to the complexity of such herbal prescriptions, studies of their pharmacological effects face challenges and have been limited to date. However, at least in traditional medicine, it is clinically more important and relevant to study herbal formulas rather than single herb extract. Sipjeondaebo-tang (SDT; Shiquandabu in Chinese, Juzentaihoto in Japanese) comprised 12 medicinal herbs and can tonify vital energy (also called "qi") and blood [11]. Thus, SDT has been used to treat lassitude, anemia, and anorexia in traditional Korean medicine [12]. Modern scientific evidence suggests that SDT has a variety of pharmacological activities, including antitumor [13-15], antioxidant [16-18], and neuroprotective [19] activities. In addition, SDT ameliorates the anorexia and hepatotoxicity induced by carbon tetrachloride $\left(\mathrm{CCl}_{4}\right)[16]$, steatosis and fibrosis in response to methionine- and cholinedeficient diets [20], steatosis and necroinflammation caused by high fat diet [21], and the hepatocarcinogenesis by diethylnitrosamine [15] in experimental animals. Although the beneficial effects of SDT in diverse type of liver disease might result from its antioxidant and anti-inflammatory activities, the underlying molecular mechanisms are not fully understood. Therefore, we investigate the in vitro and in vivo hepatoprotective effects of SDT against oxidative stress to elucidate the underlying molecular mechanism.
TABLE 1: Herbal constitution of Sipjeondaebo-tang (SDT).

\begin{tabular}{lc}
\hline Name of medical herb & Contents in the prescription $(\mathrm{g})$ \\
\hline Angelicae Gigantis Radix & 45.0 \\
Cnidii Rhizoma & 45.0 \\
Paeoniae Radix & 45.0 \\
Rehmanniae Rhizoma Preparata & 45.0 \\
Ginseng Radix & 45.0 \\
Atractylodis Rhizoma Alba & 45.0 \\
Poria Sclerotium & 45.0 \\
Glycyrrhizae Radix et Rhizoma & 45.0 \\
Astragali Radix & 37.5 \\
Cinnamomi Cortex & 37.5 \\
Zingiberis Rhizoma Crudus & 37.5 \\
Zizyphi Fructus & 37.5 \\
\hline
\end{tabular}

\section{Materials and Methods}

2.1. Reagents. AA, compound C, and STO-609 were purchased from Calbiochem (San Diego, CA, USA). Antibodies directed poly(ADP-ribose)polymerase (PARP), caspase-3, B cell lymphoma- (Bcl-) 2, phosphorylated AMPK $\alpha$, phosphorylated acetyl-CoA carboxylase (ACC), ACC, phosphorylated $\mathrm{Ca}^{2+} /$ calmodulin-dependent kinase kinase 2 (CaMKK2), liver kinase B1 (LKB1), and horseradish peroxidase-conjugated secondary antibodies were obtained from Cell Signaling Technology (Beverly, MA, USA). Anti-AMPK $\alpha$ and anti-CaMKK2 antibodies were supplied from Santa Cruz Biotechnology (Santa Cruz, CA, USA). Anti-nitrotyrosine (NT) and anti-4-hydroxynonenal (4$\mathrm{HNE}$ ) antibodies were purchased from Millipore (Temecula, CA, USA) and Abcam (Cambridge, UK), respectively. Fluo-4-acetoxymethyl ester (Fluo-4) was obtained from Invitrogen (Carlsbad, CA, USA). 3-(4,5-dimethylthiazol-2yl)-2,5-diphenyl-tetrazolium bromide (MTT), rhodamine $123,2^{\prime}, 7^{\prime}$-dichlorofluorescein diacetate (DCFH-DA), $\mathrm{CCl}_{4}$, anti- $\beta$-actin antibody, and other reagents were supplied from Sigma-Aldrich (St. Louis, MO, USA).

2.2. Preparation of the SDT. Medicinal herbs consisting SDT were supplied from Daewon Pharmacy (Daegu, Korea) (Table 1). SDT was prepared by boiling $510.0 \mathrm{~g}$ of SDT in $2 \mathrm{~L}$ of water for $3 \mathrm{~h}$. The water extracts of SDT were filtered through a $0.2 \mu \mathrm{m}$ filter paper (Nalgene, New York, NY, USA) and were lyophilized by a vacuum evaporator. The yield of lyophilized SDT was $27.08 \%$, and the lyophilized SDT was stored at $-20^{\circ} \mathrm{C}$ until use.

2.3. Chemical Profiling of SDT. To examine chemical profiles of SDT, SDT and individual standard compounds were analyzed by ultraperformance liquid chromatography (UPLC) system (Waters ACQUITY ${ }^{\mathrm{TM}}$ UPLC system, Waters Corp., Milford, MA, USA) with Waters ACQUITY ${ }^{\mathrm{TM}}$ photodiode array detector, Waters ACQUITY ${ }^{\mathrm{TM}} \mathrm{BEH} \mathrm{C}_{18}$ column $(1.7 \mu \mathrm{m}$, $2.1 \times 100 \mathrm{~mm})$, and Empower software. The samples $(2 \mu \mathrm{L}$ each) dissolved in methanol were eluted using a $2 \%$ to $100 \%$ acetonitrile gradient solution containing $0.1 \%$ of formic acid. 
Flow rate was $0.4 \mathrm{~mL} / \mathrm{min}$. The glycyrrhizic acid was detected at the wave length of $254 \mathrm{~nm}$. Calycosin-7-O- $\beta$-D-glucose, cinnamic acid, 6-gingerol, and 5-hydroxymethyl-2-furfural were detected at $280 \mathrm{~nm}$. Paeoniflorin and ferulic acid were detected at $230 \mathrm{~nm}$, decursin at $330 \mathrm{~nm}$, and ginsenoside Rg1 at $203 \mathrm{~nm}$, respectively. Concentrations of each compound in SDT were quantified based on peak areas and retention times.

2.4. Cell Culture and Treatment. HepG2 cells (a human hepatocyte-derived cell line) and HeLa cells (a human cervical cancer cell line) were purchased from American Type Culture Collection (Rockville, MD, USA) and cultured in Dulbecco's modified Eagle's medium containing $100 \mathrm{U} / \mathrm{mL}$ of penicillin, $100 \mu \mathrm{g} / \mathrm{mL}$ of streptomycin, and $10 \%$ fetal bovine serum at $37^{\circ} \mathrm{C}$ with $5 \% \mathrm{CO}_{2}$. For all experiments, the cells were grown to $80-90 \%$ confluency and starved serum for 12 h. HepG2 cells were treated with AA and iron, as described previously [9]. Briefly, cells were incubated with $10 \mu \mathrm{M}$ of AA for $12 \mathrm{~h}$ and then subsequently exposed to $5 \mu \mathrm{M}$ of iron for $1 \mathrm{~h}$. $30-1000 \mu \mathrm{g} / \mathrm{mL}$ of SDT was pretreated $1 \mathrm{~h}$ before AA treatment. For some experiments, compound $\mathrm{C}(10 \mu \mathrm{M})$ or STO-609 $(1 \mu \mathrm{g} / \mathrm{mL})$ was added to the medium $1 \mathrm{~h}$ prior to SDT treatment.

2.5. Cell Viability Assay. After treatments, viable cells were stained with MTT $(0.5 \mathrm{mg} / \mathrm{mL})$ for $4 \mathrm{~h}$ according to the previous report [21]. The relative cell viability was defined as the $\%$ of untreated control cells.

2.6. Preparation of Whole Cell Lysates and Immunoblot Analysis. Whole cell lysates were prepared, as previously described [22]. Briefly, the cells were lysed in radioimmunoprecipitation assay buffer containing protease inhibitor and phosphatase inhibitor cocktail (Thermo Fisher Scientific Inc., Rockford, IL, USA). After incubation for $1 \mathrm{~h}$ on ice, cell lysates were centrifuged at $10,000 \times g$ for $10 \mathrm{~min}$. Protein concentration was quantified using a bicinchoninic acid assay kit (Thermo Fisher Scientific Inc.). Equal amounts of protein were resolved by sodium dodecyl sulfate-polyacrylamide gel electrophoresis and then transferred to nitrocellulose or polyvinylidene fluoride membranes (Amersham Biosciences, Buckinghamshire, UK). After incubating membrane with primary and secondary antibodies, immunoreactive proteins of interest were visualized by enhanced chemiluminescence detection kit (Amersham Biosciences) and image analyzing system (Imager 600, Amersham Biosciences). Equal protein loadings were verified by $\beta$-actin immunoblotting. Band intensity of protein interest was quantified by Image J software (NIH; http://imagej.nih.gov/ij).

2.7. Measurement of Reduced GSH. The level of reduced GSH in cell homogenates was determined by using a GSH BIOXYTECH GSH-400 kit (Oxis International Inc., Portland, OR, USA), as previously described [9]. GSH content was measured at $405 \mathrm{~nm}$ using a microplate reader (Infinite 200 PRO, Tecan, Männedorf, Switzerland) and was normalized by cell number.
2.8. Measurement of Hydrogen Peroxide $\left(\mathrm{H}_{2} \mathrm{O}_{2}\right)$ Production. The level of $\mathrm{H}_{2} \mathrm{O}_{2}$ production was detected by adding the DCFH-DA [22]. After treatment, the cells were stained with $20 \mu \mathrm{M}$ of DCFH-DA for $1 \mathrm{~h}$. The fluorescence emitted by dichlorofluorescein was measured at excitation/emission wavelengths of $485 / 530 \mathrm{~nm}$ using a microplate reader (Tecan).

2.9. Measurement of Mitochondrial Membrane Potential $(M M P)$. MMP was measured by using rhodamine 123, a membrane permeable cationic fluorescent dye [22]. After treatment, the cells were stained with $0.05 \mu \mathrm{g} / \mathrm{mL}$ of rhodamine 123 for $1 \mathrm{~h}$ and were harvested by trypsinization. The change in MMP was detected using a flow cytometer (Partec, Münster, Germany). In each analysis, 10,000 cells were recorded.

2.10. Measurement of Intracellular $\mathrm{Ca}^{2+}$ Levels. To determine levels of intracellular $\mathrm{Ca}^{2+}$, HepG2 cells were stained with $5 \mu \mathrm{M}$ of Fluo- 4 for $30 \mathrm{~min}$ at $37^{\circ} \mathrm{C}$ and then washed with PBS to remove Fluo- 4 in medium. After addition of SDT $(300 \mu \mathrm{g} / \mathrm{mL})$, the fluorescence intensities for $15 \mathrm{~min}$ were measured at excitation/emission wavelengths of 488/520 nm using a microplate reader (Tecan). Changes on fluorescence intensities for $10 \mathrm{~min}$ were calculated as area under the curve (AUC) using Graphpad prism 7 (Graphpad software, Inc., CA, USA).

2.11. Animal Experiments. Animal experiments were conducted according to the national regulations regarding the use and welfare of laboratory animals and were approved by the Institutional Animal Care and Use Committee in Daegu Haany University (Approval No. DHU2015-057). ICR mice at 6 weeks of age (male, 28-30 g) were supplied from Orient Bio, Inc. (Seongnam, Korea) and acclimatized for one week. Mice $(\mathrm{N}=16)$ were maintained with a supply of filtered pathogen-free air, provided with commercial chow (Nestle Purina PetCare Korea, Seoul, Korea) and water ad libitum at a temperature between $20^{\circ} \mathrm{C}$ and $23^{\circ} \mathrm{C}$ with a $12 \mathrm{~h}$ light/dark cycle and relative humidity of $50 \%$. SDT dissolved in water was orally administrated to mice at the dose of 300 and $500 \mathrm{mg} / \mathrm{kg} / \mathrm{day}$ for 4 consecutive days. One hour after the last SDT administration, mice were intraperitoneally injected $10 \% \mathrm{CCl}_{4}(0.5 \mathrm{~mL} / \mathrm{kg})$ diluted with corn oil. Blood and liver tissues were collected at $24 \mathrm{~h}$ after $\mathrm{CCl}_{4}$ injection.

2.12. Blood Biochemistry. Alanine aminotransferase (ALT) and aspartate aminotransferase (AST) activities in serums were measured using an automated blood chemistry analyzer (Photometer 5010, Robert Riele GmbH \& Co KG, Berlin, Germany).

2.13. Histopathology and Immunohistochemistry. Histopathology and immunohistochemistry were conducted as previously described [9]. Briefly, liver tissues were fixed with $10 \%$ neutral buffered formalin, embedded in paraffin, sectioned (3-4 $\mu \mathrm{m})$, and then stained with hematoxylin and eosin. The numbers of degenerative hepatocytes (cells/1000 
hepatocytes) and the numbers of infiltrated inflammatory cells (cells $/ \mathrm{mm}^{2}$ of hepatic parenchyma) were observed under light microscope (Model 80i, Nikon, Tokyo, Japan). NT and 4-HNE in hepatic tissues were stained using primary antibodies and avidin-biotin-peroxidase and peroxidase substrate kit (Vector Labs, Burlingame, CA, USA). Positive cells were defined as having NT and 4-HNE immunoreactivity intensities of $>20 \%$. All histopathological and immunohistochemical parameters were calculated using an automated image analyzer (iSolution FL ver 9.1, IMT i-Solution Inc., Quebec, Vancouver, Canada) and the histopathologist that performed this analysis was unaware of sample details.

2.14. Statistical Analysis. The unpaired Student's $t$-test was used for determining the significance between two groups. One-way analysis of variance was used to assess the significance among experimental groups, followed by Tukey's honest significance difference or Dunnett's T3 as post hoc analysis. All data are expressed means \pm standard deviation (SD) of at least three separate experiments. $P$ values less than 0.05 were considered as statistical differences of significance.

\section{Results}

3.1. Quantification of Nine Marker Compounds in SDT. Based on the Korean pharmacopoeia, we used glycyrrhizic acid for quality control of Glycyrrhizae Radix et Rhizoma, paeoniflorin for Paeoniae Radix, ferulic acid for Cnidii Rhizoma, 5-hydroxymethyl-2-furfural for Rehmanniae Rhizoma Preparata, calycosin-7-O- $\beta$-D-glucose for Astragali Radix, decursin for Angelicae Gigantis Radix, ginsenoside Rg1 for Ginseng Radix, cinnamic acid for Cinnamomi Cortex, and 6-gingerol for Zingiberis Rhizoma Crudus (Ministry of Food and Drug Safety, https://www.mfds.go.kr/herbmed and https://ezdrug.mfds.go.kr/, accessed 17 Mar 2106, in Korean). Before investigating the hepatoprotective effects of SDT, we quantified nine chemical markers in SDT via UPLC under optimized conditions (Figure S1). The SDT used in the present study contained $253.62 \pm 4.43 \mathrm{ppm}$ of glycyrrhizic acid, $147.07 \pm 1.82 \mathrm{ppm}$ of paeoniflorin, $49.72 \pm 1.7 \mathrm{ppm}$ of ferulic acid, $32.31 \pm 1.62 \mathrm{ppm}$ of 5-hydroxymethyl-2-furfural, $22.97 \pm 0.83 \mathrm{ppm}$ of calycosin-7-O- $\beta$-D-glucose, $4.74 \pm 0.72$ ppm of decursin, $2.62 \pm 0.03$ ppm of ginsenoside Rg1, $1.82 \pm$ $0.44 \mathrm{ppm}$ of cinnamic acid, and $0.87 \pm 0.05 \mathrm{ppm}$ of 6 -gingerol (Figure 1(a)).

3.2. SDT Inhibits AA Plus Iron-Mediated Apoptosis. We and others have reported that treatment with AA plus iron induces oxidative stress-mediated apoptosis in HepG2 cells $[3,8,9]$. To examine whether SDT protects cells from oxidative stress-mediated cytotoxicity, HepG2 cells were pretreated with $30-1000 \mu \mathrm{g} / \mathrm{mL}$ of SDT for $1 \mathrm{~h}$ and subsequently exposed to AA $(10 \mu \mathrm{M}, 12 \mathrm{~h})$ and iron $(5 \mu \mathrm{M}, 1 \mathrm{~h})$; then, cell viability was determined using the MTT assay. As expected, treatment with AA plus iron significantly decreased cell viability $(38.70$ $\pm 4.99 \%$ ) compared with the untreated control. However, pretreatment with 300 and $1000 \mu \mathrm{g} / \mathrm{mL}$ of SDT completely prevented the reduction in cell viability induced by AA plus iron, while 30 and $100 \mu \mathrm{g} / \mathrm{mL}$ of SDT pretreatment did not (Figure 1(b)). Treatment with SDT alone at up to 1000 $\mu \mathrm{g} / \mathrm{mL}$ did not change the viability of HepG2 cells (Figure S2(a)). tert-butyl hydroperoxide is an organic peroxide that provokes oxidative stress in HepG2 cells [22]. In parallel with the results of AA plus iron treatment, SDT pretreatment (100 and $300 \mu \mathrm{g} / \mathrm{mL}$ ) significantly prevented tert-butyl hydroperoxide-mediated cytotoxicity in HepG2 cells (Figure S2(b)). Because the maximal preventive effect against AA plus iron-mediated cytotoxicity was observed with pretreatment above $300 \mu \mathrm{g} / \mathrm{mL}$ of SDT, $300 \mu \mathrm{g} / \mathrm{mL}$ of SDT was used in subsequent experiments. Next, we monitored expression levels of apoptosis-related proteins by immunoblot analysis. Pretreatment with SDT $(300 \mu \mathrm{g} / \mathrm{mL})$ in the presence of AA plus iron decreased the expression of the cleaved forms of PARP and caspase- 3 and increased the expression of Bcl2 (Figure 1(c)). These results indicate that SDT can prevent oxidative stress-mediated apoptosis in HepG2 cells.

3.3. SDT Inhibits AA Plus Iron-Mediated Oxidative Stress and Mitochondrial Dysfunction. To investigate whether the reduction in oxidative stress conferred by SDT contributes to the protection of cells against AA plus iron, we measured intracellular concentrations of reduced GSH, the major endogenous antioxidant. Treatment with AA plus iron depleted GSH levels in HepG2 cells. However, pretreatment with SDT $(300 \mu \mathrm{g} / \mathrm{mL})$ significantly prevented GSH depletion by AA plus iron (Figure 2(a)). Next, we monitored intracellular levels of $\mathrm{H}_{2} \mathrm{O}_{2}$ after staining cells with DCFHDA. Treatment with AA plus iron increased $\mathrm{H}_{2} \mathrm{O}_{2}$ production, whereas SDT pretreatment significantly reduced $\mathrm{H}_{2} \mathrm{O}_{2}$ production (Figure 2(b)). Intracellular levels of GSH and $\mathrm{H}_{2} \mathrm{O}_{2}$ did not differ between the treatment with SDT alone and untreated control. Because impairment of mitochondrial respiration results in intracellular ROS accumulation, we further examined whether SDT could restore MMP. From the flow cytometry results, AA plus iron increased the subpopulation with low rhodamine 123 fluorescence intensity (RN1 subpopulation), and SDT pretreatment significantly inhibited the increase in the RN1 subpopulation. SDT alone had no effect on the RN1 subpopulation (Figure 2(c)). These results suggest that SDT protects cells by reducing oxidative stress and restores mitochondrial integrity.

3.4. AMPK Activation Is Essential for SDT-Mediated Cytoprotection. Because we and others have reported several medicinal herbs and natural products that prevent oxidative stress via AMPK activation [4,7-10], we first monitored the effect of SDT $(300 \mu \mathrm{g} / \mathrm{mL})$ on the temporal responses of AMPK and ACC (a representative downstream substrate of AMPK) phosphorylation. Based on immunoblot results, maximal increases in AMPK and ACC phosphorylation were observed at $0.5 \mathrm{~h}$ after SDT treatment, after which the levels gradually decreased. SDT treatment did not change AMPK and ACC expression (Figure 3(a)). To explore whether AMPK activation by SDT contributes to the protection of mitochondria and cells from AA plus iron, HepG2 cells were pretreated with $10 \mu \mathrm{M}$ of compound $\mathrm{C}$ (a chemical inhibitor 


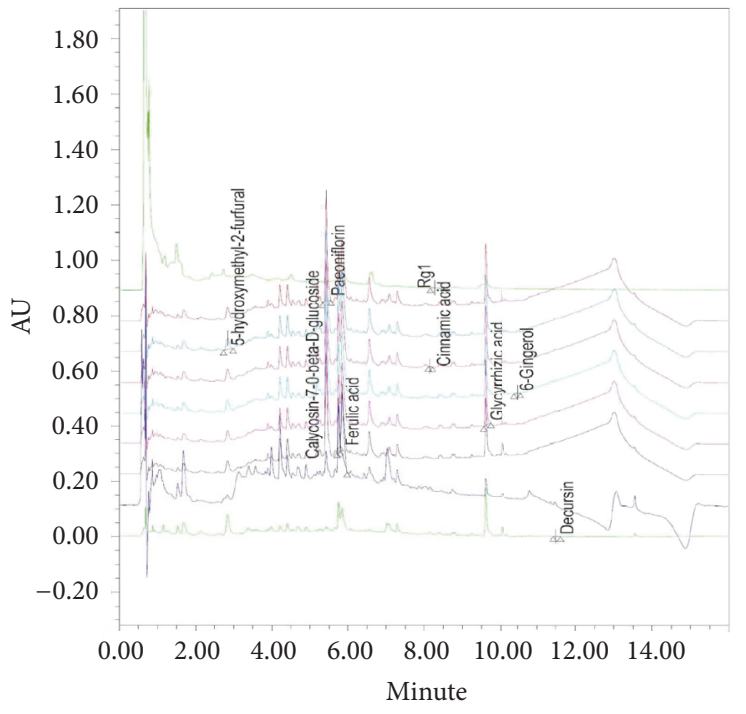

(a)

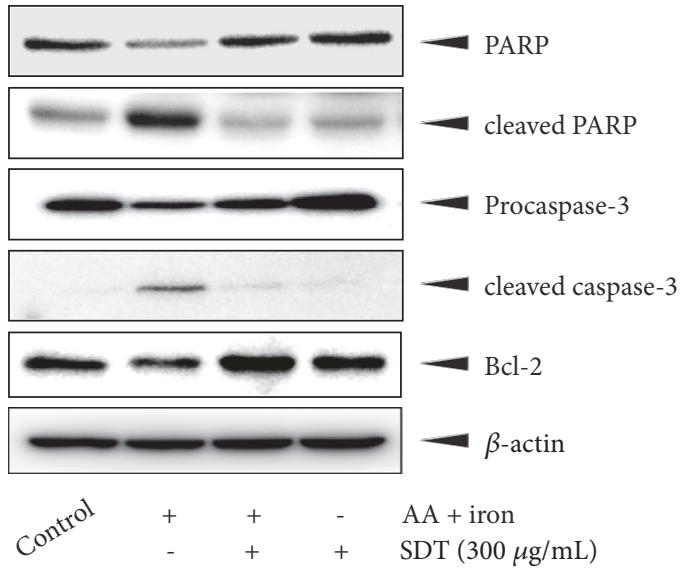

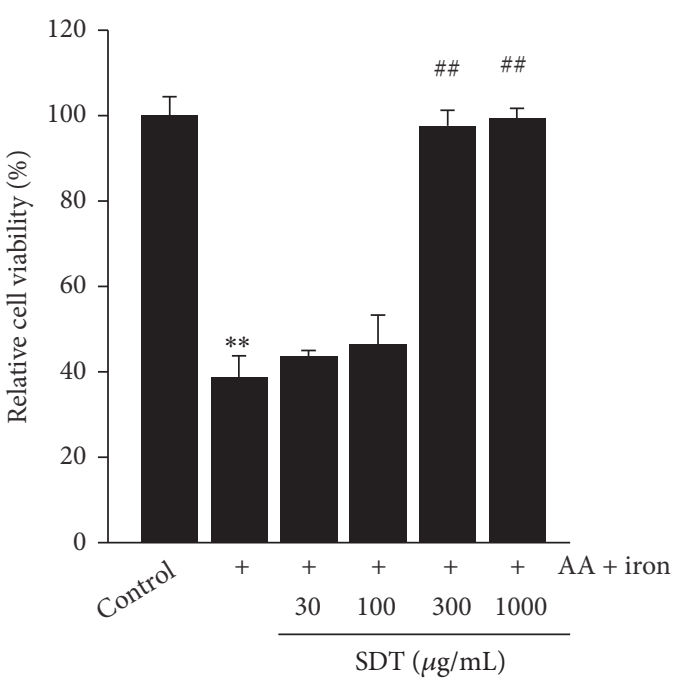

(b)
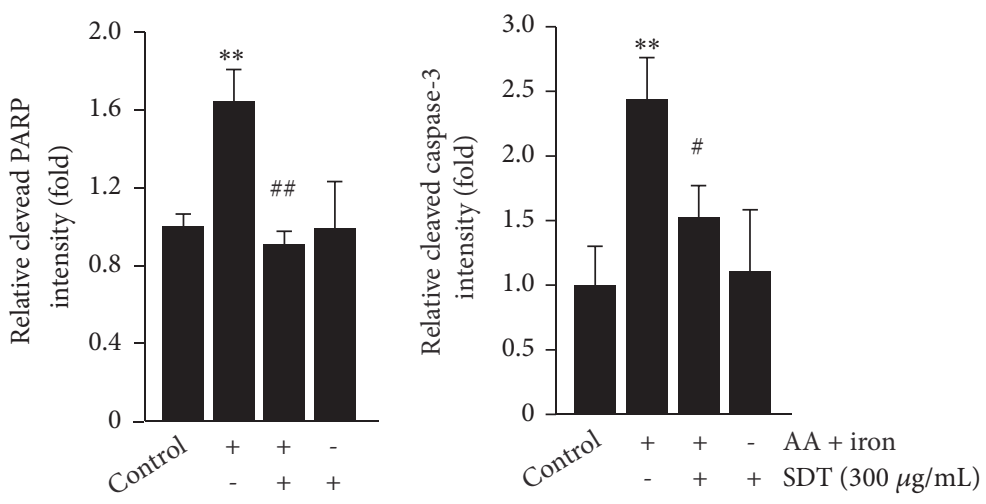

(c)

FIGURE 1: The effect of Sipjeondaebo-tang (SDT) on AA plus iron-mediated apoptosis. (a) UPLC chromatogram of nine marker compounds in SDT. The chromatograms were obtained at $280 \mathrm{~nm}$ (for 5-hydroxymethyl-2-furfural, calycosin-7-O- $\beta$-D-glucoside, cinnamic acid, and 6gingerol), $230 \mathrm{~nm}$ (for paeoniflorin and ferulic acid), $203 \mathrm{~nm}$ (for ginsenoside Rg1), $254 \mathrm{~nm}$ (for glycyrrhizic acid), and $330 \mathrm{~nm}$ (for decursin), respectively. (b) Cell viability. HepG2 cells were pretreated with $30-1000 \mu \mathrm{g} / \mathrm{mL}$ of SDT for $1 \mathrm{~h}$, exposed to $10 \mu \mathrm{M}$ of AA for $12 \mathrm{~h}$, and treated with $5 \mu \mathrm{M}$ iron for $1 \mathrm{~h}$. Relative cell viabilities were measured by MTT assay. (c) Changes on apoptosis-related proteins. Cells were incubated with $300 \mu \mathrm{g} / \mathrm{mL}$ of SDT for $1 \mathrm{~h}$ and then treated with AA plus iron, as described in panel (b). Equal protein loading was verified by $\beta$-actin immunoblotting (left). The intensities of cleaved forms of PARP and caspase- 3 were quantified by scanning densitometry (middle and right). All values represent mean \pm SD of three separated experiments; significant versus untreated control, ${ }^{* *} P<0.01$; significant versus AA plus iron, ${ }^{\# \#} P<0.01$ and ${ }^{\#} P<0.05$.

of AMPK), and exposed to SDT, AA, and iron. Pretreatment with compound $\mathrm{C}$ alone in HepG2 cells tended to increase the RN1 subpopulation. In addition, compound C inhibited the protective effect of SDT on AA plus iron-mediated mitochondrial membrane leakage (Figure 3(b)). Moreover, restorations of procaspase- 3 expression and cell viability by SDT were blocked by pretreatment with compound C (Figure 3(c)). These results imply that SDT-induced AMPK activation is responsible for protecting cells and mitochondria. Activation. To identify the upstream kinase of SDT-mediated
AMPK activation, HepG2 cells were stained with $5 \mu \mathrm{M}$ of Fluo-4, and intracellular levels of $\mathrm{Ca}^{2+}$ were measured. Treatment with SDT $(300 \mu \mathrm{g} / \mathrm{mL})$ rapidly increased the Fluo-4 fluorescence intensity, which peaked after $10 \mathrm{~min}$ and was sustained for 15 min (Figure 4(a), left). When the changes in fluorescence intensity for $10 \mathrm{~min}$ were calculated as AUC, SDT treatment significantly increased intracellular $\mathrm{Ca}^{2+}$ levels compared with the untreated control (Figure 4(a), right). In addition, treatment with SDT significantly increased CaMKK2 phosphorylation (Figure 4(b)), and the maximum level of CaMKK2 phosphorylation was detected at $0.5 \mathrm{~h}$, concurrent with the maximum AMPK phosphorylation 


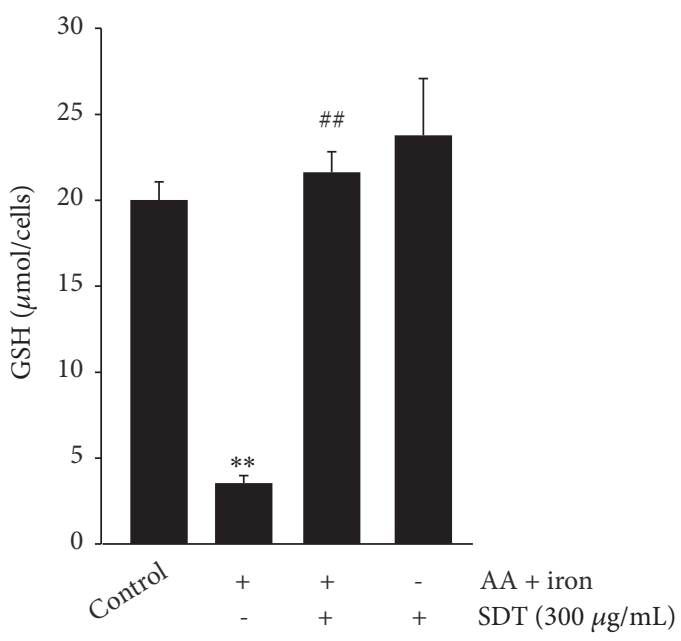

(a)
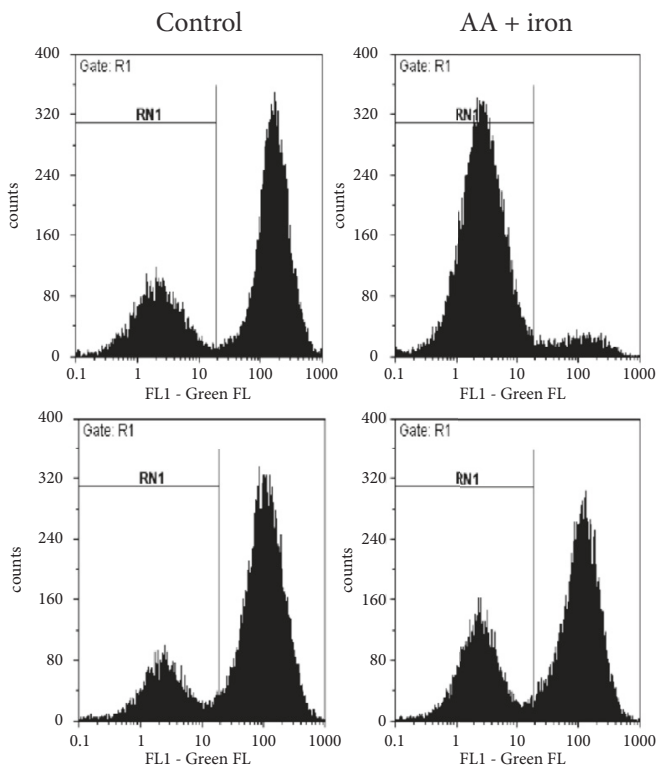

$\mathrm{AA}+$ iron $+\mathrm{SDT}$

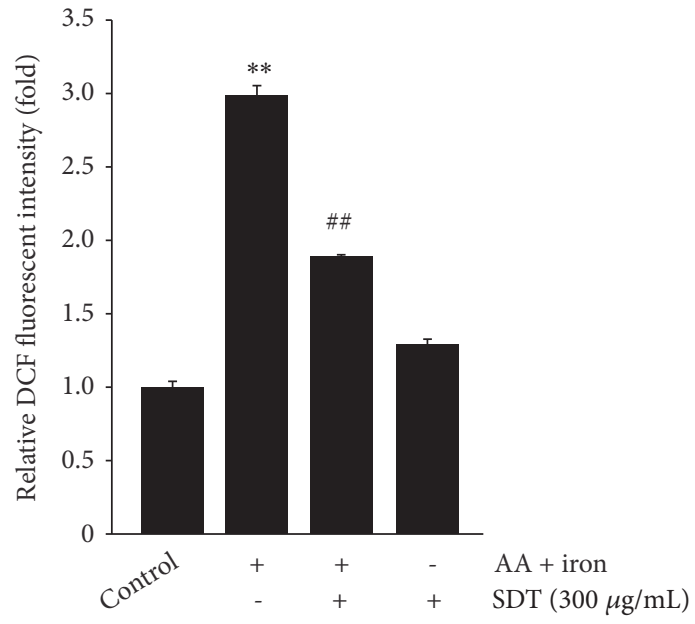

(b)

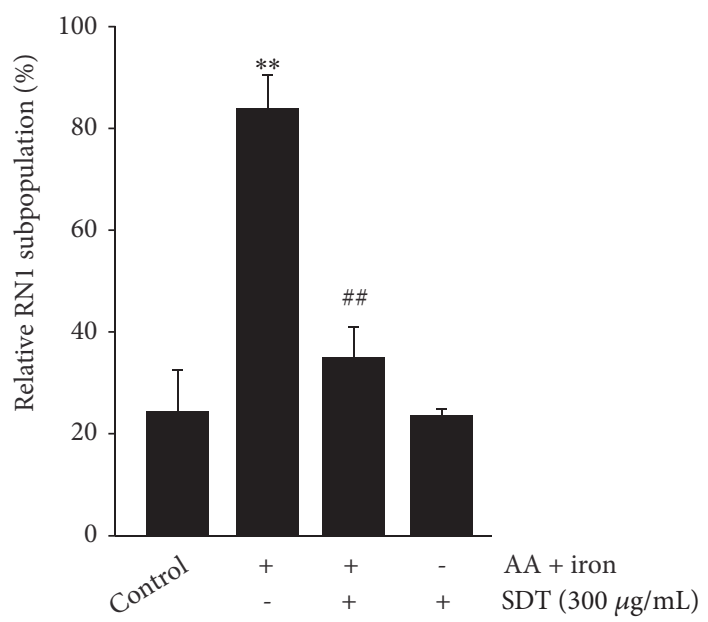

(c)

FIGURE 2: The effect of SDT on AA plus iron-mediated oxidative stress and mitochondrial dysfunction. (a) Cellular GSH contents. HepG2 cells were treated SDT $(300 \mu \mathrm{g} / \mathrm{mL})$, AA $(10 \mu \mathrm{M})$, and iron $(5 \mu \mathrm{M})$, as described in Figure $1(\mathrm{~b})$. Reduced GSH contents were estimated in cell homogenates. (b) $\mathrm{H}_{2} \mathrm{O}_{2}$ production. Treated cells were stained with $20 \mu \mathrm{M}$ DCFH-DA for 30 min, and intracellular levels of $\mathrm{H}_{2} \mathrm{O}_{2}$ were measured using dichlorofluorescein fluorescence intensity. (c) MMP. Fluorescence intensity of rhodamine 123-stained cells was monitored using a flow cytometer (left). Cell subpopulation with low rhodamine 123 fluorescence intensity (RN1 fraction) was represented as percentages of total cell analyzed (right). All values represent mean \pm SD of three separated experiments; significant versus untreated control, ${ }^{* *} P<0.01$; significant versus AA plus iron, ${ }^{\# \#} P<0.01$.

(Figure 3(a)). It has been known that LKB1, another upstream kinase of AMPK, is deficient in HeLa cells [23]. When HeLa cells were treated with SDT, SDT phosphorylated AMPK and ACC (Figure 4(c)). In addition, pretreatment with STO-609 $(1 \mu \mathrm{g} / \mathrm{mL}$; a representative CaMKK2 inhibitor) decreased SDT-dependent AMPK and ACC phosphorylation (Figure 4(d), upper). Moreover, STO-609 blocked the effects of SDT on AA plus iron-mediated $\mathrm{H}_{2} \mathrm{O}_{2}$ production (Figure 4(d), lower) and cytotoxicity (Figure 4(e)). These results suggest that SDT activates AMPK via CaMKK2 phosphorylation.

3.6. SDT Protects $\mathrm{CCl}_{4}$-Induced Liver Injury in Mice. To expand on our finding that SDT protects cells from oxidative stress-mediated apoptosis in vitro, 300 or $500 \mathrm{mg} / \mathrm{kg}$ of SDT was administered to ICR mice for 4 days, after which $\mathrm{CCl}_{4}$ was injected to induce oxidative stress-mediated liver injury. The activities of ALT and AST, which are serum 

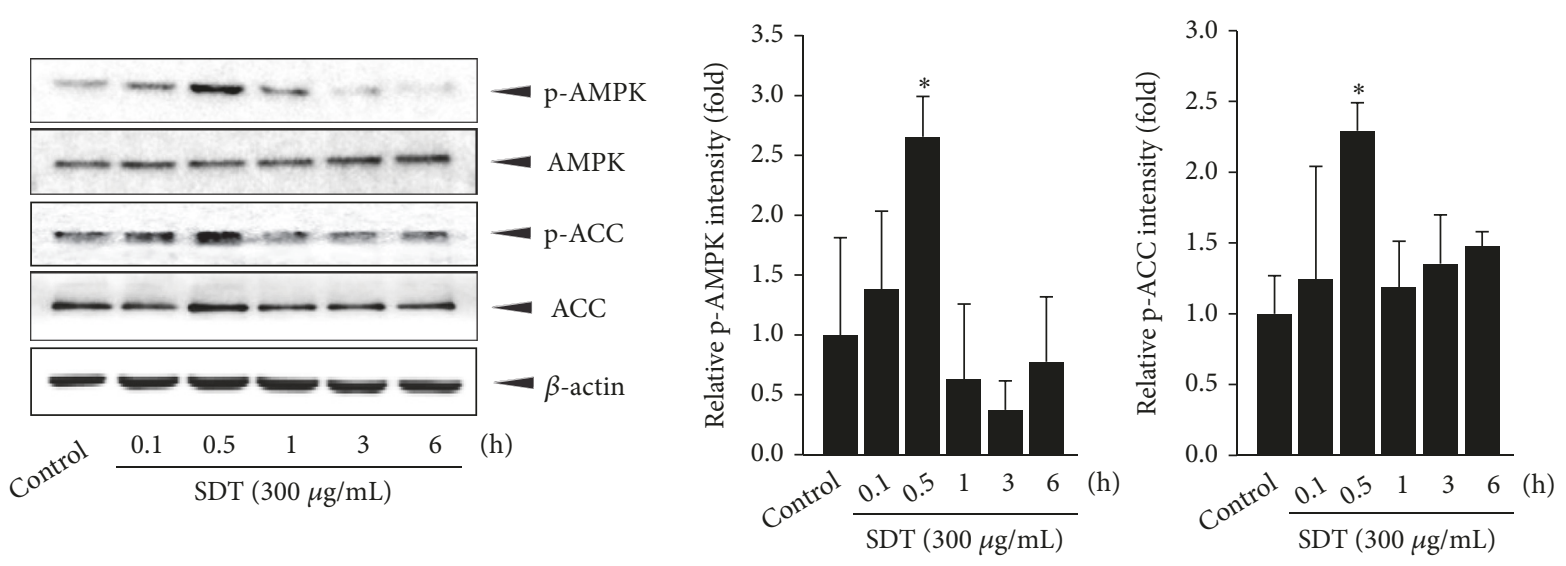

(a)
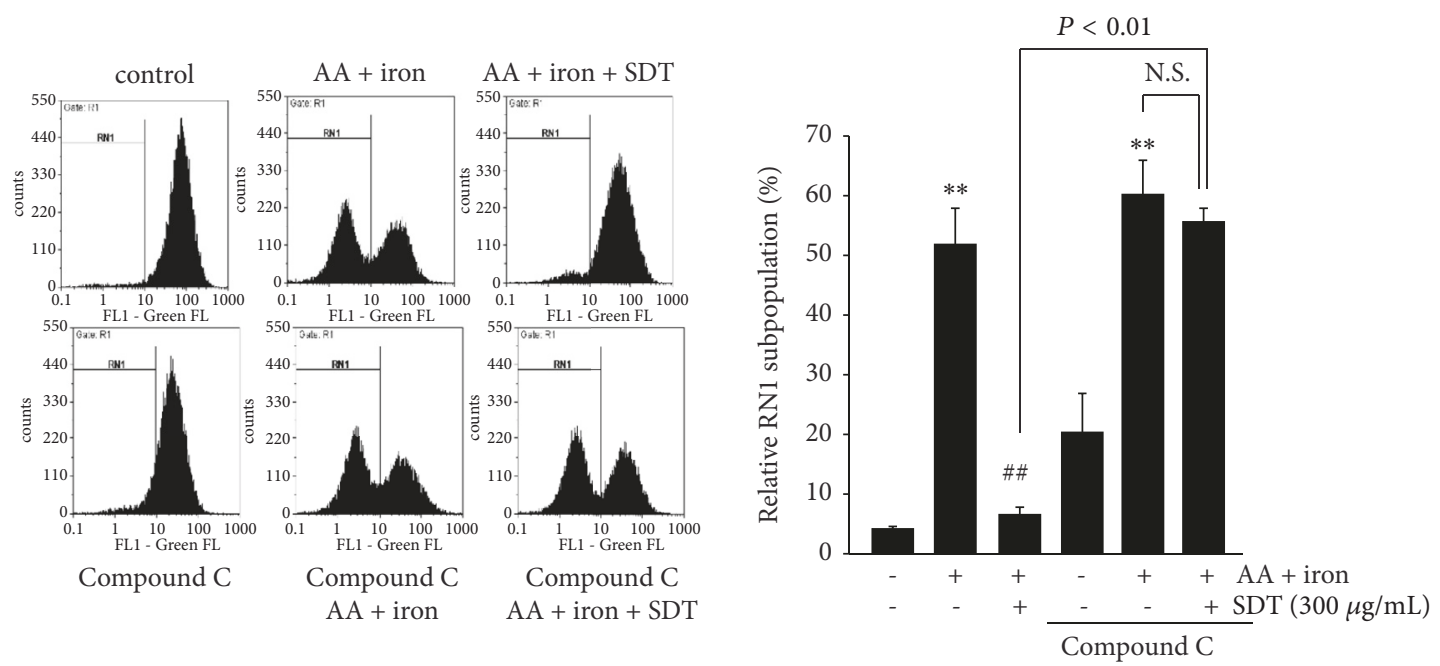

(b)
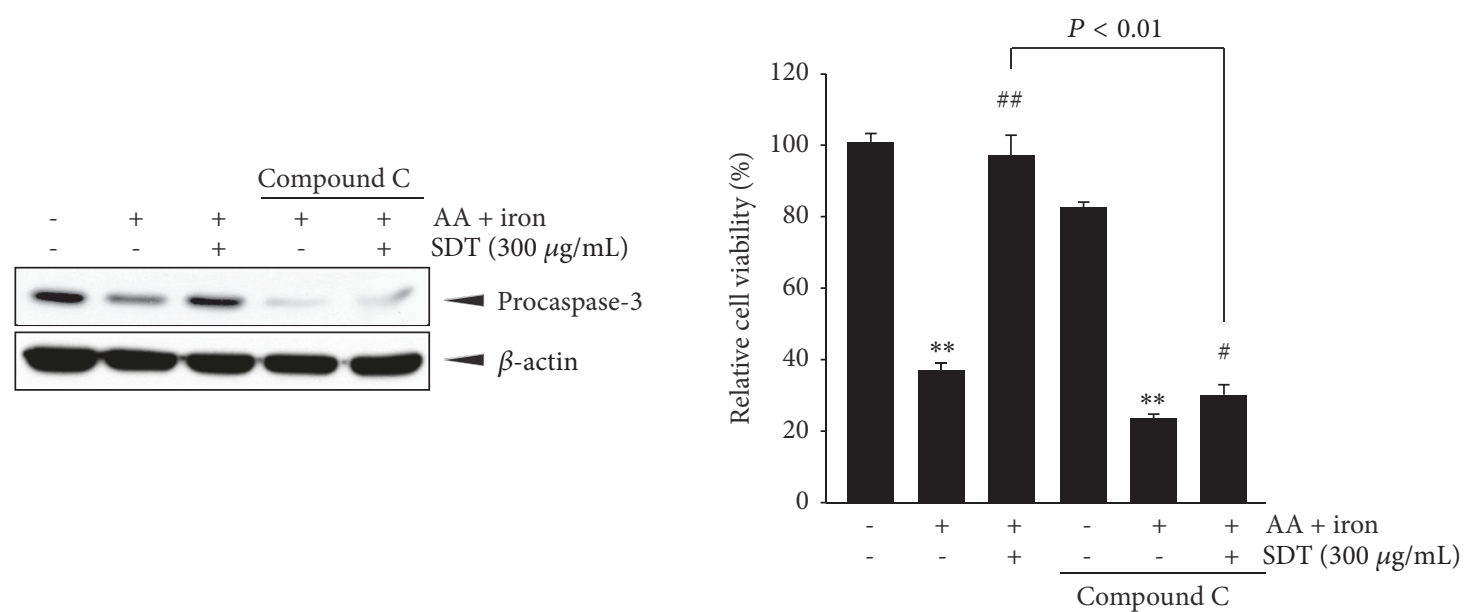

(c)

FIGURE 3: The effect of SDT on AMPK activation. (a) AMPK phosphorylation. Immunoblot analyses were conducted using HepG2 cell lysates that had been treated with SDT $(300 \mu \mathrm{g} / \mathrm{mL})$ for indicated time periods. Equal protein loading was verified by $\beta$-actin immunoblotting (left). Relative levels of phosphorylated AMPK (middle) and phosphorylated ACC (right) were quantified by scanning densitometry. (b) Effect of compound C on SDT-mediated mitochondrial protection. $10 \mu \mathrm{M}$ of compound C-pretreated HepG2 cells ( $1 \mathrm{~h}$ ) were exposed to SDT, AA, and iron. (c) Effect of compound C on SDT-mediated cytoprotection. Expression of procaspase 3 (left) and relative cell viability (right) were monitored by immunoblot and MTT analysis, respectively. All values represent mean \pm SD of three separated experiments; significant versus untreated control, ${ }^{* *} P<0.01$ and ${ }^{*} P<0.05$; significant versus AA plus iron, ${ }^{\# \#} P<0.01$ and ${ }^{\#} P<0.05$; NS, not significant. 


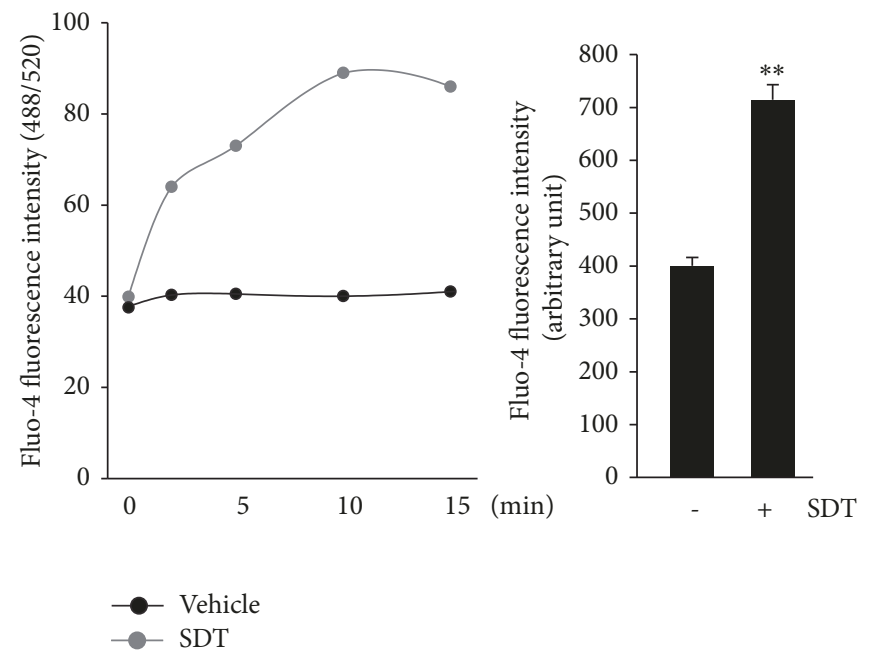

(a)

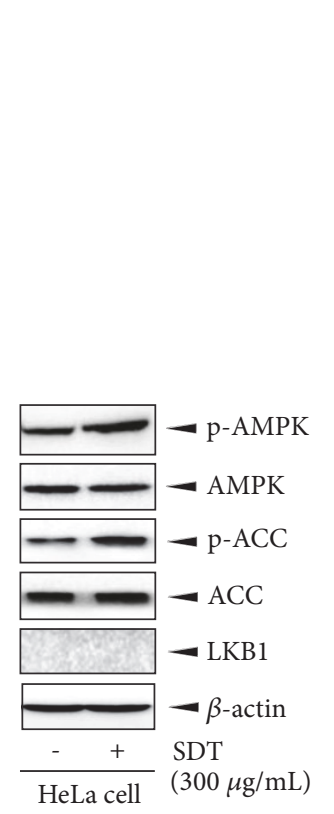

(c)

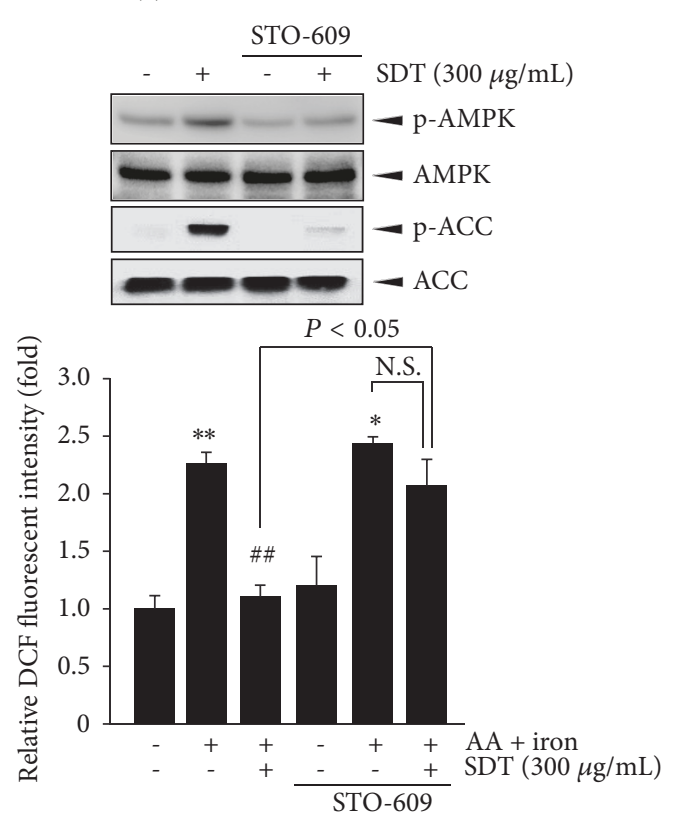

(d)
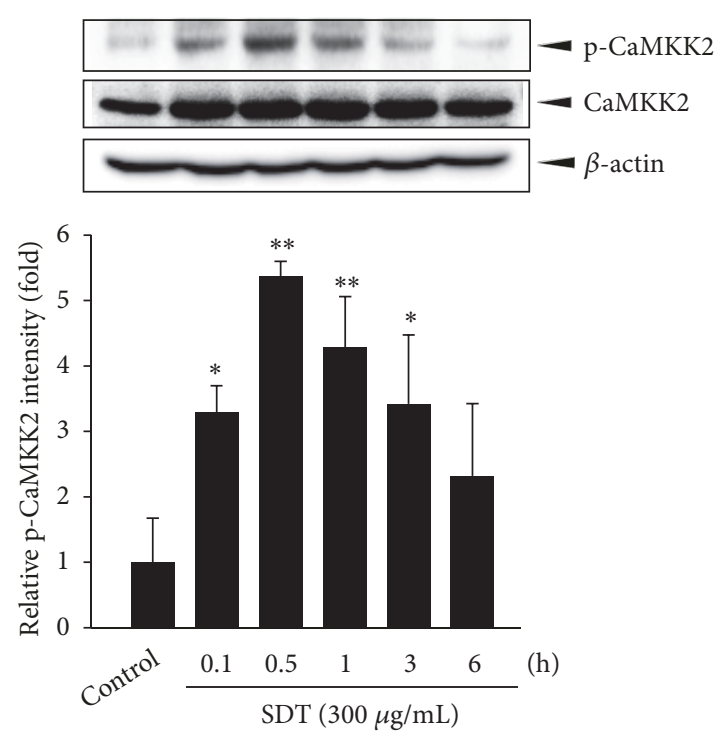

(b)

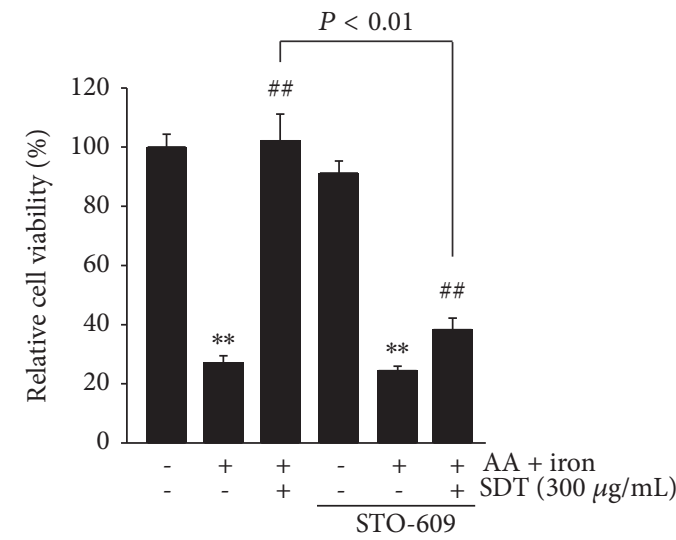

(e)

FIGURE 4: The effect of SDT on CaMKK2 activation. (a) Effect of SDT on intracellular Ca ${ }^{2+}$ level. Fluo-4 stained HepG2 cells were incubated with SDT $(300 \mu \mathrm{g} / \mathrm{mL})$, and fluorescence intensity for $15 \mathrm{~min}$ was monitored (left). Changes in fluorescence intensity for $10 \mathrm{~min}$ were calculated as AUC (right). (b) CaMKK2 phosphorylation by SDT. CaMKK2 phosphorylation was determined by using HepG2 cell lysates that had been treated with SDT $(300 \mu \mathrm{g} / \mathrm{mL})$ for indicated times. Equal protein loading was verified by $\beta$-actin immunoblotting (upper). Intensity of phosphorylated CaMKK2 was quantified by scanning densitometry (lower). (c) Effect of SDT on HeLa cells. HeLa cells were treated with 300 $\mu \mathrm{g} / \mathrm{mL}$ SDT for $0.5 \mathrm{~h}$, and AMPK and ACC phosphorylation were determined by immunoblot analysis. Phenotype of HeLa cells was verified by LKB1 immunoblotting. (d) Effect of STO-609 on the inhibition of AA plus iron-mediated $\mathrm{H}_{2} \mathrm{O}_{2}$ production by SDT. SDT-dependent phosphorylation of AMPK (upper) and reduction of $\mathrm{H}_{2} \mathrm{O}_{2}$ production (lower) were monitored in STO-609 $(1 \mu \mathrm{g} / \mathrm{mL}, 1 \mathrm{~h}) \mathrm{pretreated} \mathrm{cells.} \mathrm{(e)}$ Effect of STO-609 on SDT-mediated cytoprotection. The relative cell viability was determined using MTT assay. All values represent mean \pm $\mathrm{SD}$ of three separated experiments; significant versus untreated control, ${ }^{* *} P<0.01$ and ${ }^{*} P<0.05$; significant versus AA plus iron, ${ }^{\# \#} P<0.01$; NS, not significant.

biochemical markers of liver injury, significantly increased at 1 day after $\mathrm{CCl}_{4}$ injection compared with vehicle-injected mice. However, oral administration of SDT for 4 consecutive days tended to reduce serum ALT and AST activities in a dose-dependent manner, and a significant difference was only observed between the $500 \mathrm{mg} / \mathrm{kg}$ of SDT and $\mathrm{CCl}_{4}$ groups (Figure 5(a)). Histomorphometric analysis of hematoxylin and eosin-stained hepatic tissues indicated that the 

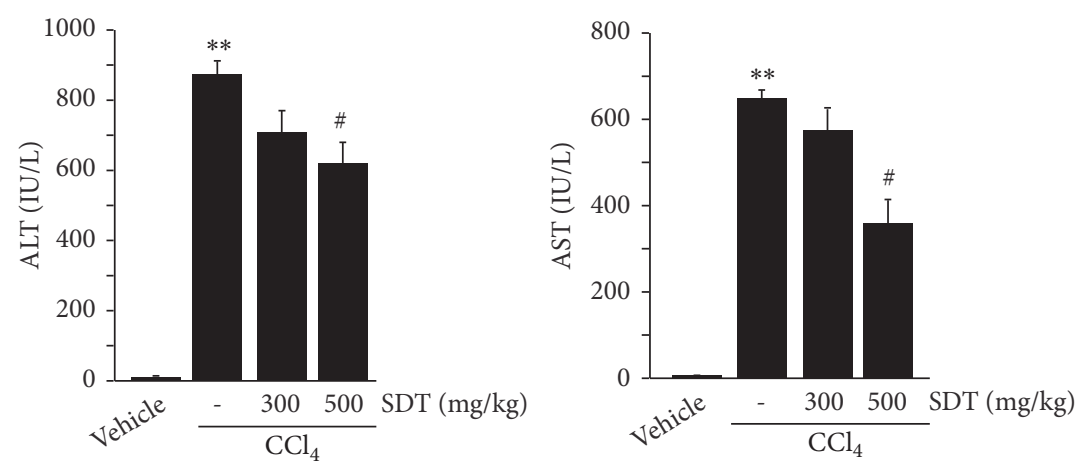

(a)
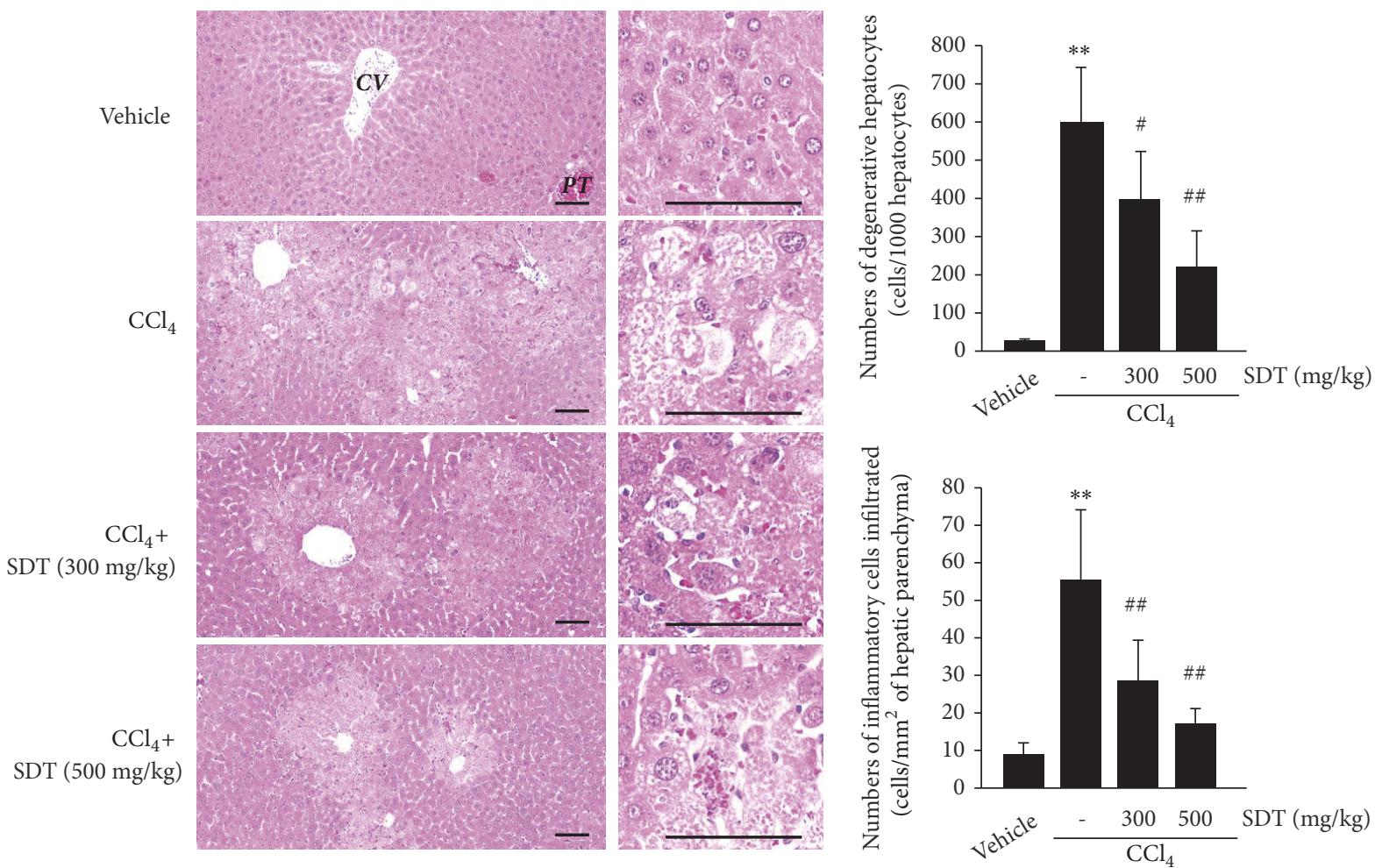

(b)

FIGURE 5: The effect of SDT on $\mathrm{CCl}_{4}$-induced acute liver injury. (a) ALT and AST activities. Mice were orally administered SDT (300 or 500 $\mathrm{mg} / \mathrm{kg}$ ) for 4 days. One hour after last SDT administration, mice were intraperitoneally injected $\mathrm{CCl}_{4}(0.5 \mathrm{~mL} / \mathrm{kg}$ ). Serum ALT (left) and AST (right) activities were detected $24 \mathrm{~h}$ after $\mathrm{CCl}_{4}$ injection. (b) The representative histological profiles of the liver tissues. Scale bars indicate 120 $\mu \mathrm{m}$ (left). The numbers of degenerative hepatocytes (upper right) and infiltrated inflammatory cells (lower right) were quantified using an automated image analyzer. All values represent mean $\pm \mathrm{SD}$ of four mice (for (a)) or eight historical fields from four mice (for (b)); significant versus vehicle-treated group, ${ }^{* *} P<0.01$; significant versus $\mathrm{CCl}_{4}$-treated group, ${ }^{\# \#} P<0.01$ and ${ }^{\#} P<0.05$; $\mathrm{CV}$, central vein; PT, portal triad.

number of degenerative hepatocytes showing acute cellular swelling, severe fatty changes, and eosinophilic necrosis was significantly increased after $\mathrm{CCl}_{4}$ injection, and SDT administration prevented hepatocyte degeneration in a dosedependent manner. In addition, SDT significantly reduced infiltration of inflammatory cells in hepatic parenchyma by $\mathrm{CCl}_{4}$ (Figure 5(b)). To examine whether SDT protects the liver from $\mathrm{CCl}_{4}$-induced toxicity by reducing oxidative stress in vivo, liver tissues were stained with NT (a marker of nitrosative stress) and 4-HNE (a marker of lipid peroxidation). SDT administration significantly reduced the numbers of NT- and 4-HNE-immunoreactive cells in hepatic tissues in a dose-dependent manner (Figure 6). These results indicate that SDT can protect the liver from oxidative stress in vivo.

\section{Discussion}

Use of herbal medicines has become common worldwide due to their multiple therapeutic activities and few side effects [24]. SDT is one of the most well-known herbal prescriptions for treating weakness after illness (e.g., anorexia, fatigue, and anemia) in Korea, China, and Japan [11, 12]. 

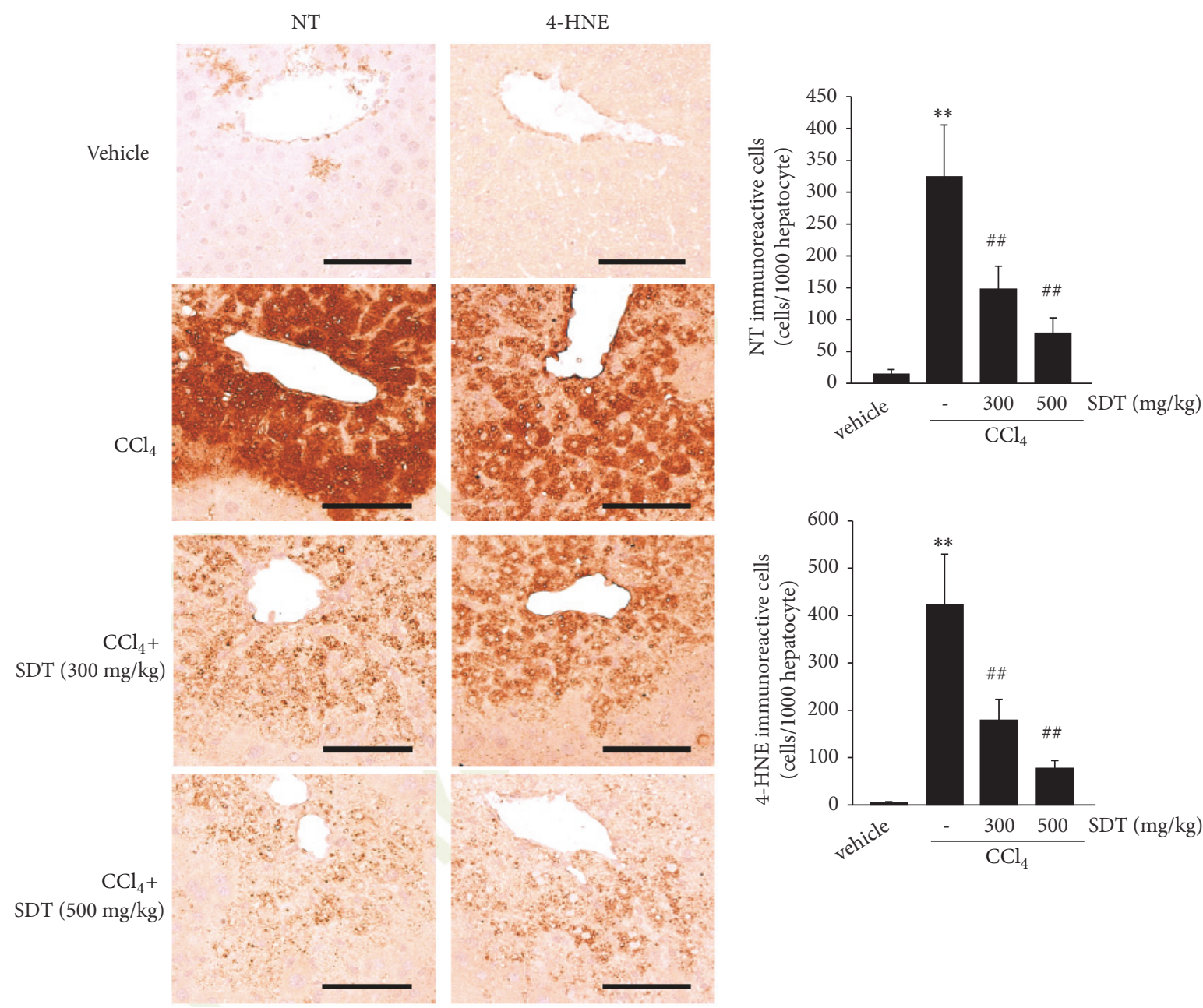

FIGURE 6: The effect of SDT on $\mathrm{CCl}_{4}$-induced oxidative stress in hepatic tissues. Immunohistochemical analyses in liver tissues were conducted using anti-NT or anti-4-HNE antibody (left). The numbers of NT- (upper right) and 4-HNE-positive cells (lower right) were measured using an automated image analyzer. Scale bars indicate $120 \mu \mathrm{m}$. All values represent mean \pm SD of eight historical fields from four mice; significant versus vehicle-treated group, ${ }^{* *} P<0.01$; significant versus $\mathrm{CCl}_{4}$-treated group, ${ }^{\# \#} P<0.01$.

Although several studies have reported the effects of SDT against oxidative stress in the liver $[15,16]$, the associated molecular mechanisms by which SDT prevents oxidative stress have not been fully elucidated. Before testing the antioxidant potential of SDT, we conducted a UPLC analysis to assess the quality of SDT and observed chemical markers representing nine medicinal herbs effectively solubilized in the SDT water extract. Of the nine marker compounds, glycyrrhizic acid, ferulic acid, cinnamic acid, 6-gingerol, 5-hydroxymethyl-2-furfural, paeoniflorin, and ginsenoside Rg1 have been reported to reduce oxidative stress in experimental hepatic disorders [25-31]. However, the concentrations of the nine marker compounds were too low to explain the potent hepatoprotective effects of SDT. Thus, these compounds in combination with unidentified compounds might confer protection of the liver from oxidative stress; additional studies are required to identify the major contributors to the hepatoprotective effect of SDT.
Based on reports that AA in the presence of iron synergistically accelerates oxidative stress-mediated apoptosis [3], we used an AA plus iron exposure model in HepG2 cells to investigate the cytoprotective effect of SDT and elucidate the molecular mechanism in vitro. Here, we showed that pretreatment with 300 or $1000 \mu \mathrm{g} / \mathrm{mL}$ SDT completely prevented AA plus iron-mediated cytotoxicity. Moreover, SDT inhibited the GSH depletion, $\mathrm{H}_{2} \mathrm{O}_{2}$ production, and mitochondrial membrane impairment induced by AA plus iron. SDT also attenuated the reduction of $\mathrm{Bcl}-2$, an antiapoptotic protein and decreased the activation of apoptosis executors (e.g., procaspase-3 and PARP cleavage). Overall, these results suggest that SDT has hepatoprotective effects against AA plus iron-mediated apoptosis by reducing oxidative stress.

We previously reported that eupatilin, tryptanthrin, isorhamnetin, Paeonia obovata, and Buddleja officinalis protect cells from the effects of AA plus iron via AMPK activation $[4,7-9,32]$. AMPK is regarded as a master regulator of cellular homeostasis related to oxidative and 
metabolic stress [5]. In our previous study, blockage of AMPK activation by a chemical inhibitor (e.g., compound C) or dominant negative mutant of AMPK failed to reduce the $\mathrm{H}_{2} \mathrm{O}_{2}$ generation, mitochondrial membrane impairment, and cytotoxicity induced by AA plus iron $[4,7,9,32]$. Similarly, the present results showed that SDT increased AMPK and ACC phosphorylation. Moreover, SDT-mediated protection of the mitochondrial membrane and cells was completely blocked by pretreatment with compound C. These results provide evidence that SDT acts as a hepatoprotective herbal medicine via AMPK activation.

CaMKK2 (also known as CaMKK $\beta$ ), LKB1, and TGF$\beta$-activated kinase 1 have been suggested to phosphorylate directly within the activation loop (i.e., Thr172) of the catalytic $\alpha$ subunit $[5,6,33]$. Different upstream kinases seem to phosphorylate context-dependently AMPK. Microeconomic metabolic stress phosphorylates AMPK via nucleotidedependent LKB1 activation, while increases in intracellular $\mathrm{Ca}^{2+}$ by external stimuli (i.e., macroeconomic metabolic stress) lead to CaMKK2 activation, which phosphorylates Thr172 and activates AMPK in a nucleotide-independent manner [34-36]. Tissue distribution studies of LKB1 reveal that LKB1 mediates the AMPK phosphorylation in every tissue. However, CaMKK2-dependent AMPK phosphorylation appears nearly in neurons, $\mathrm{T}$ cells, and liver [37, 38]. Moreover, systemic and liver specific deletion of CaMKK2 ameliorates diet-induced metabolic stress [38, 39]. In the present study, we showed that SDT increased intracellular $\mathrm{Ca}^{2+}$ levels and CaMKK2 phosphorylation. In addition, SDT could phosphorylate AMPK in HeLa cells (representative LKB1-deficient cells). When cells were pretreated with STO609, a selective CaMKK2 inhibitor, SDT-mediated AMPK, and ACC phosphorylation decreased. Thus, LKB1 does not appear to be an important upstream kinase for SDT-mediated AMPK phosphorylation at least in our experimental system. Moreover, pretreatment with STO-609 reduced the cytoprotective ability of SDT and sustained $\mathrm{H}_{2} \mathrm{O}_{2}$ production against AA plus iron. These results suggest that CaMKK2 is an upstream signaling molecule of SDT-dependent AMPK activation.

We previously found that eupatilin increased Sestrin2mediated AMPK phosphorylation and reduced oxidative stress via autophagy induction [8]. In addition, downstream p38 mitogen-activated protein kinase (p38 MAPK) activation and GSK- $3 \beta$ inhibition are also involved in AMPK-mediated cytoprotection against AA plus iron $[7,9]$. To explore the role of autophagy and p38 MAPK in SDT-mediated cytoprotection, HepG2 cells were additionally pretreated with chemical inhibitors of autophagy (bafilomycin A1 and 3methyladenine) or p38 MAPK (SB203580). However, the cytoprotective ability of SDT against AA plus iron was sustained in the presence of autophagy inhibitors (Figures S3(a) and S3(b)). Interestingly, our preliminary experiments using chemical inhibitors showed that the cytoprotective effect of SDT partly reduced by pretreatment with SB203580 (Figure S3(c)). Moreover, SDT-mediated cytoprotection was completely inhibited by Akt inhibitor, LY294002 (Figure S3(d)). In parallel with previous observation [9], pretreatment with a GSK-3 inhibitor (SB216763) partly (but significantly) alleviated AA plus iron-mediated cytotoxicity (data not shown). Studies have suggested that AMPK increases inactive phosphorylation of GSK-3 $\beta$ through the activation of the phosphatidylinositol-3-kinase/Akt signaling pathway [4042]. Therefore, SDT appears to protect cells from oxidative stress in an autophagy-independent and Akt/GSK-3 $\beta / \mathrm{p} 38$ MAPK-dependent manner. Further studies are needed to explore the relationship between AMPK and Akt in SDT treatment.

$\mathrm{CCl}_{4}$ is one of the most commonly used hepatotoxins to examine the hepatoprotective effects of beneficial compounds in vivo $[4,43]$. Metabolic conversion of $\mathrm{CCl}_{4}$ in liver produces trichloromethyl and trichloromethyl peroxy radicals, which cause the changes in membrane permeability and provoke oxidative stress-mediated hepatocyte damage in zone 3 of the liver [4, 43, 44]. In parallel with previous studies [4, $16]$, the present results showed that a single $\mathrm{CCl}_{4}$ injection increased ALT and AST activity in mice serum, indicative of liver damage. Although SDT tended to decrease the levels of serum markers of hepatotoxicity in a dose-dependent manner, the reductions in ALT and AST activity were statistically significant only in mice administered with 500 $\mathrm{mg} / \mathrm{kg}$ of SDT. Histopathological analysis of hepatic tissues revealed increases in degenerated hepatocytes around the central veins after $\mathrm{CCl}_{4}$ injection. Moreover, inflammatory cells infiltrated into the hepatic parenchyma by $\mathrm{CCl}_{4}$. However, administration of SDT for 4 consecutive days dosedependently attenuated these changes. Reactive nitrogen species mainly produced via oxidative burst of infiltrated inflammatory cells rapidly penetrate neighboring hepatic parenchyma, accelerating dysfunction of biomolecules by covalent modification of reactive nitrogen species. In addition, free radicals produced by $\mathrm{CCl}_{4}$ cause lipid peroxidation and decrease membrane integrity. Thus, immunostaining against nitrated tyrosine and 4-hydroxynonenal have been commonly used to monitor oxidative stress in the liver [4, $7,9]$. Our results showed that SDT significantly reduced the increases in NT- and 4-HNE-positive cells induced by $\mathrm{CCl}_{4}$. These results provide evidence that SDT inhibits oxidative (nitrative) stress, protecting hepatocytes against the acute injuries caused by $\mathrm{CCl}_{4}$.

In conclusion, the results of present study indicate that SDT blocks AA plus iron-mediated toxicity by reducing GSH depletion, intracellular $\mathrm{H}_{2} \mathrm{O}_{2}$ production, and mitochondrial impairment. In addition, CaMKK2-dependent AMPK phosphorylation has an essential role in the cytoprotective effects of SDT. Meanwhile, histopathological and immunohistochemical examination revealed that SDT can ameliorate $\mathrm{CCl}_{4}$-mediated acute hepatotoxicity by reducing oxidative stress in vivo. These findings suggest that SDT is a beneficial hepatoprotective herbal medicine against oxidative stress that act via activation of the CaMKK2-AMPK signaling pathway.

\section{Abbreviations}

AA: Arachidonic acid

ACC: Acetyl-CoA carboxylase

ALT: Alanine aminotransferase 
AMPK: $\quad$ AMP-activated protein kinase

AST: Aspartate aminotransferase

AUC: $\quad$ Area under the curve

Bcl-2: $\quad$ B cell lymphoma-2

CaMKK2: $\quad \mathrm{Ca}^{2+} /$ calmodulin-dependent protein kinase kinase 2

$\mathrm{CCl}_{4}$ : Carbon tetrachloride

DCFH-DA: $2^{\prime}, 7^{\prime}$-Dichlorofluorescein diacetate

Fluo-4: $\quad$ Fluo-4-acetoxymethyl ester

GSH: Glutathione

GSK-3 $\beta$ : Glycogen synthase- $3 \beta$

4-HNE: 4-Hydroxynonenal

$\mathrm{H}_{2} \mathrm{O}_{2}$ : Hydrogen peroxide

LKB1: $\quad$ Liver kinase B1

MMP: $\quad$ Mitochondrial membrane potential

MTT: 3-(4,5-Dimethylthiazol-2-yl)-2,5-diphenyltetrazolium

bromide

NT: $\quad$ Nitrotyrosine

p38 MAPK: p38 mitogen-activated protein kinase

PARP: $\quad$ Poly(ADP-ribose)polymerase

ROS: $\quad$ Reactive oxygen species

SD: $\quad$ Standard deviation

SDT: $\quad$ Sipjeondaebo-tang

UPLC: Ultraperformance liquid chromatography.

\section{Data Availability}

The data used to support the findings of this study are available from the corresponding author upon request.

\section{Conflicts of Interest}

The authors declare that they have no conflicts of interest.

\section{Authors' Contributions}

Sang Mi Park, Sung Woo Kim, and Eun Hye Jung contributed equally to this work.

\section{Acknowledgments}

This study was supported by the National Research Foundation of Korea (NRF) funded by Korea government (MSIP) (Grants No. 2018R1A5A2025272 and 2012 R1A5A2A42671316). S. W. Kim would like to thank the Ph.D. degree program at Daegu Haany University for completing the thesis through part of this work.

\section{Supplementary Materials}

Figure S1: representative UPLC chromatogram of nine marker compounds. Figure S2: cell viability assay. Figure S3: effect of some chemical inhibitors on SDTmediated cytoprotection. (Supplementary Information) (Supplementary Materials)

\section{References}

[1] H. Cichoz-Lach and A. Michalak, "Oxidative stress as a crucial factor in liver diseases," World Journal of Gastroenterology, vol. 20, no. 25, pp. 8082-8091, 2014.

[2] M. A. Balboa and J. Balsinde, "Oxidative stress and arachidonic acid mobilization," Biochimica et Biophysica Acta (BBA) Molecular and Cell Biology of Lipids, vol. 1761, no. 4, pp. 385391, 2006.

[3] S. M. Shin and S. G. Kim, "Inhibition of arachidonic acid and iron-induced mitochondrial dysfunction and apoptosis by oltipraz and novel 1,2-dithiole-3-thione congeners," Molecular Pharmacology, vol. 75, no. 1, pp. 242-253, 2009.

[4] J. Y. Jung, C. W. Lee, S. M. Park et al., "Activation of AMPK by Buddleja officinalis maxim. flower extract contributes to protecting hepatocytes from oxidative stress," Evidence-Based Complementary and Alternative Medicine, vol. 2017, Article ID 9253462, 15 pages, 2017.

[5] D. Garcia and R. J. Shaw, "AMPK: Mechanisms of Cellular Energy Sensing and Restoration of Metabolic Balance," Molecular Cell, vol. 66, no. 6, pp. 789-800, 2017.

[6] B. Sid, J. Verrax, and P. B. Calderon, "Role of AMPK activation in oxidative cell damage: Implications for alcohol-induced liver disease," Biochemical Pharmacology, vol. 86, no. 2, pp. 200-209, 2013.

[7] E. H. Jung, J. Y. Jung, H. L. Ko et al., “Tryptanthrin prevents oxidative stress-mediated apoptosis through AMP-activated protein kinase-dependent p38 mitogen-activated protein kinase activation," Archives of Pharmacal Research, vol. 40, no. 9, pp. 1071-1086, 2017.

[8] K. H. Jegal, H. L. Ko, S. M. Park et al., "Eupatilin induces Sestrin2-dependent autophagy to prevent oxidative stress," Apoptosis, vol. 21, no. 5, pp. 642-656, 2016.

[9] H. L. Ko, E. H. Jung, D. H. Jung et al., "Paeonia japonica root extract protects hepatocytes against oxidative stress through inhibition of AMPK-mediated GSK3 $\beta$," Journal of Functional Foods, vol. 20, pp. 303-316, 2016.

[10] M. S. Shin, I. J. Cho, and S. G. KIM, "Resveratrol protects mitochondria against oxidative stress through AMP-activated protein kinase-mediated glycogen synthase kinase- $3 \beta$ inhibition downstream of poly(ADP-ribose) polymerase-LKB1 pathway," Molecular Pharmacology, vol. 76, no. 4, pp. 884-895, 2009.

[11] V. Scheid, D. Bensky, A. Ellis, and R. Barolet, Chinese herbal medicine: Formulas \& Strategies, Eastlan Press, Seattle, WA, USA, 2nd edition, 2009.

[12] C. Cheon, J.-E. Yoo, H.-S. Yoo et al., "Efficacy and safety of sipjeondaebo-tang for anorexia in patients with cancer: a pilot, randomized, double-blind, placebo-controlled trial," Evidence-Based Complementary and Alternative Medicine, vol. 2017, Article ID 8780325, 9 pages, 2017.

[13] S. Ishikawa, T. Ishikawa, C. Tezuka, K. Asano, M. Sunagawa, and T. Hisamitsu, "Efficacy of juzentaihoto for tumor immunotherapy in B16 melanoma metastasis model," Evidence-Based Complementary and Alternative Medicine, vol. 2017, Article ID 6054706, 8 pages, 2017.

[14] N. Takeno, A. Inujima, K. Shinohara et al., "Immune adjuvant effect of juzentaihoto, a Japanese traditional herbal medicine, on tumor vaccine therapy in a mouse model," International Journal of Oncology, vol. 47, no. 6, pp. 2115-2122, 2015.

[15] M. Tsuchiya, H. Kono, M. Matsuda, H. Fujii, and I. Rusyn, "Protective effect of Juzen-taiho-to on hepatocarcinogenesis is mediated through the inhibition of Kupffer cell-induced 
oxidative stress," International Journal of Cancer, vol. 123, no. 11, pp. 2503-2511, 2008.

[16] H. Yoshioka, S. Fukaya, N. Miura, S. Onosaka, T. Nonogaki, and A. Nagatsu, "Suppressive effect of Kampo formula "Juzen-taihoto" on carbon tetrachloride-induced hepatotoxicity in mice," Biological \& Pharmaceutical Bulletin, vol. 39, no. 9, pp. 15641567, 2016.

[17] W.-Y. Jeon, I.-S. Shin, H.-K. Shin, and M.-Y. Lee, "Gastroprotective effect of the traditional herbal medicine, Sipjeondaebo-tang water extract, against ethanol-induced gastric mucosal injury," BMC Complementary and Alternative Medicine, vol. 14, no. 1 , article 373, 2014.

[18] T. Takata, "Effect of Saikokeishito, a Kampo medicine, on hydrogen peroxide-induced premature senescence of normal human dermal fibroblasts," Journal of Integrative Medicine, vol. 12, no. 6, pp. 495-503, 2014.

[19] H. J. Yim, J. H. Lim, M. H. Kim, U. Namgung, S. R. Lee, and I. C. Jung, "Neuroprotective activity of Sibjeondaebo-tang on A $\beta$ peptide-induced damages," Evidence-Based Complementary and Alternative Medicine, vol. 2012, Article ID 459894, 8 pages, 2012.

[20] Y. Takahashi, Y. Soejima, A. Kumagai, M. Watanabe, H. Uozaki, and T. Fukusato, "Inhibitory effects of Japanese herbal medicines sho-saiko-to and juzen-taiho-to on nonalcoholic steatohepatitis in mice," PLoS ONE, vol. 9, no. 1, Article ID e87279, 2014.

[21] Y. Takahashi, Y. Soejima, A. Kumagai, M. Watanabe, H. Uozaki, and T. Fukusato, "Japanese herbal medicines shosaikoto, inchinkoto, and juzentaihoto inhibit high-fat dietinduced nonalcoholic steatohepatitis in $\mathrm{db} / \mathrm{db}$ mice," Pathology International, vol. 64, no. 10, pp. 490-498, 2014.

[22] S. M. Park, J. R. Lee, S. K. Ku et al., "Isoliquiritigenin in licorice functions as a hepatic protectant by induction of antioxidant genes through extracellular signal-regulated kinase-mediated NF-E2-related factor-2 signaling pathway," European Journal of Nutrition, vol. 55, no. 8, pp. 2431-2444, 2016.

[23] R. L. Hurley, K. A. Anderson, J. M. Franzone, B. E. Kemp, A. R. Means, and L. A. Witters, "The Ca2+/calmodulindependent protein kinase kinases are AMP-activated protein kinase kinases," The Journal of Biological Chemistry, vol. 280, no. 32, pp. 29060-29066, 2005.

[24] H. Nasri, A. Baradaran, H. Shirzad, and M. R. Kopaei, "New concepts in nutraceuticals as alternative for pharmaceuticals," International Journal of Preventive Medicine, vol. 5, no. 12, pp. 1487-1499, 2014.

[25] N. F. Abo El-Magd, M. El-Mesery, A. El-Karef, and M. M. El-Shishtawy, "Glycyrrhizin ameliorates high fat diet-induced obesity in rats by activating NrF2 pathway," Life Sciences, vol. 193, pp. 159-170, 2018.

[26] Y. Gao, S. Chu, Q. Shao et al., "Antioxidant activities of ginsenoside Rg1 against cisplatin-induced hepatic injury through Nrf2 signaling pathway in mice," Free Radical Research, vol. 51, no. 1, pp. 1-13, 2017.

[27] D. Joshi, S. K. Srivastav, S. Belemkar, and V. A. Dixit, "Zingiber officinale and 6-gingerol alleviate liver and kidney dysfunctions and oxidative stress induced by mercuric chloride in male rats: A protective approach," Biomedicine \& Pharmacotherapy, vol. 91, pp. 645-655, 2017.

[28] Z. Ma, L. Chu, H. Liu et al., "Beneficial effects of paeoniflorin on non-alcoholic fatty liver disease induced by high-fat diet in rats," Scientific Reports, vol. 7, no. 1, 2017.
[29] P. G. Jain and S. J. Surana, "Isolation, characterization and hypolipidemic activity of ferulic acid in high-fat-diet-induced hyperlipidemia in laboratory rats," EXCLI Journal, vol. 15, pp. 599-613, 2016.

[30] S.-L. Yan, Z.-H. Wang, H.-F. Yen, Y.-J. Lee, and M.-C. Yin, "Reversal of ethanol-induced hepatotoxicity by cinnamic and syringic acids in mice," Food and Chemical Toxicology, vol. 98, pp. 119-126, 2016.

[31] W. Li, X.-N. Qu, Y. Han, S.-W. Zheng, J. Wang, and Y.-P. Wang, "Ameliorative effects of 5-hydroxymethyl-2-furfural (5-HMF) from Schisandra chinensis on alcoholic liver oxidative injury in mice," International Journal of Molecular Sciences, vol. 16, no. 2 , pp. 2446-2457, 2015.

[32] G.-Z. Dong, J.-H. Lee, S. H. Ki et al., "AMPK activation by isorhamnetin protects hepatocytes against oxidative stress and mitochondrial dysfunction," European Journal of Pharmacology, vol. 740, pp. 634-640, 2014.

[33] R. Lage, C. Diéguez, A. Vidal-Puig, and M. López, "AMPK: a metabolic gauge regulating whole-body energy homeostasis," Trends in Molecular Medicine, vol. 14, no. 12, pp. 539-549, 2008.

[34] S. A. Hawley, D. A. Pan, K. J. Mustard et al., "Calmodulindependent protein kinase kinase- $\beta$ is an alternative upstream kinase for AMP-activated protein kinase," Cell Metabolism, vol. 2, no. 1, pp. 9-19, 2005.

[35] A. Woods, K. Dickerson, R. Heath et al., " $\mathrm{Ca}^{2+} /$ calmodulindependent protein kinase kinase- $\beta$ acts upstream of AMPactivated protein kinase in mammalian cells," Cell Metabolism, vol. 2, no. 1, pp. 21-33, 2005.

[36] L. A. Witters, B. E. Kemp, and A. R. Means, "Chutes and Ladders: The search for protein kinases that act on AMPK," Trends in Biochemical Sciences, vol. 31, no. 1, pp. 13-16, 2006.

[37] M. M. Mihaylova and R. J. Shaw, "The AMPK signalling pathway coordinates cell growth, autophagy and metabolism," Nature Cell Biology, vol. 13, no. 9, pp. 1016-1023, 2011.

[38] K. A. Anderson, F. Lin, T. J. Ribar et al., "Deletion of CaMKK2 from the liver lowers blood glucose and improves whole-body glucose tolerance in the mouse," Molecular Endocrinology, vol. 26, no. 2, pp. 281-291, 2012.

[39] K. A. Anderson, T. J. Ribar, F. Lin et al., "Hypothalamic CaMKK2 contributes to the regulation of energy balance," Cell Metabolism, vol. 7, no. 5, pp. 377-388, 2008.

[40] J. Yan, C. Wang, Y. Jin et al., "Catalpol ameliorates hepatic insulin resistance in type 2 diabetes through acting on AMPK/NOX4/PI3K/AKT pathway," Pharmacological Research, vol. 130, pp. 466-480, 2018.

[41] X. Ci, J. Zhou, H. Lv, Q. Yu, L. Peng, and S. Hua, "Betulin exhibits anti-inflammatory activity in LPS-stimulated macrophages and endotoxin-shocked mice through an AMPK/AKT/Nrf2dependent mechanism," Cell Death and Disease, vol. 8, no. 5, p. e2798, 2017.

[42] T. Zheng, X. Yang, D. Wu et al., "Salidroside ameliorates insulin resistance through activation of a mitochondria-associated AMPK/PI3K/Akt/GSK3 $\beta$ pathway," British Journal of Pharmacology, vol. 172, no. 13, pp. 3284-3301, 2015.

[43] L. W. D. Weber, M. Boll, and A. Stampfl, "Hepatotoxicity and mechanism of action of haloalkanes: carbon tetrachloride as a toxicological model," Critical Reviews in Toxicology, vol. 33, no. 2, pp. 105-136, 2003.

[44] J. Vandenberghe, "Hepatotoxicology: mechanisms of liver toxicity and methodological aspects," in Toxicology: Principles and Applications, R. J. M. Niesink, J. de Vries, and M. A. Hollinger, Eds., CRC Press, Boca Raon, FL, USA, 1st edition, 1996. 


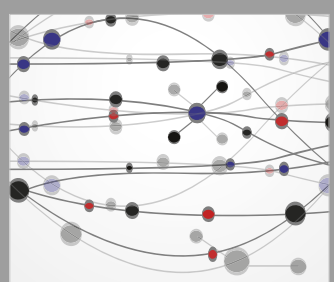

The Scientific World Journal
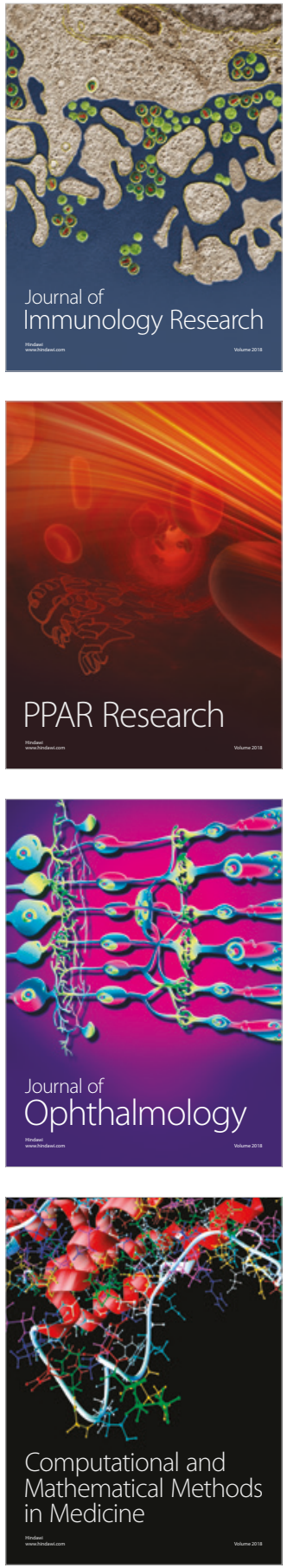

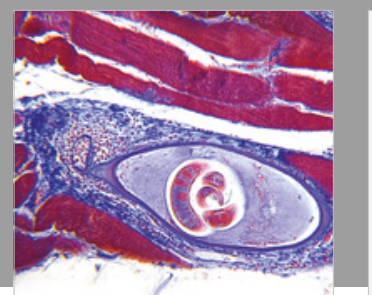

Gastroenterology Research and Practice

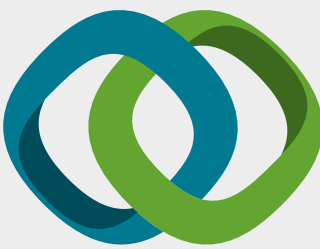

\section{Hindawi}

Submit your manuscripts at

www.hindawi.com
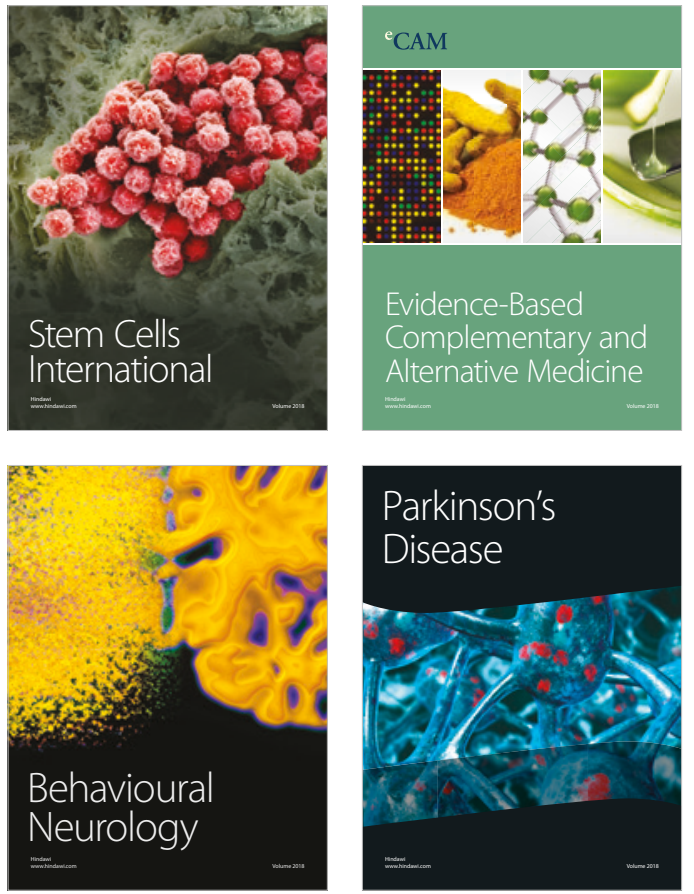

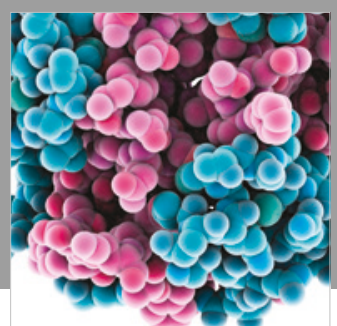

ournal of

Diabetes Research

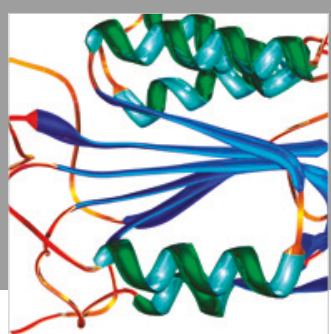

Disease Markers
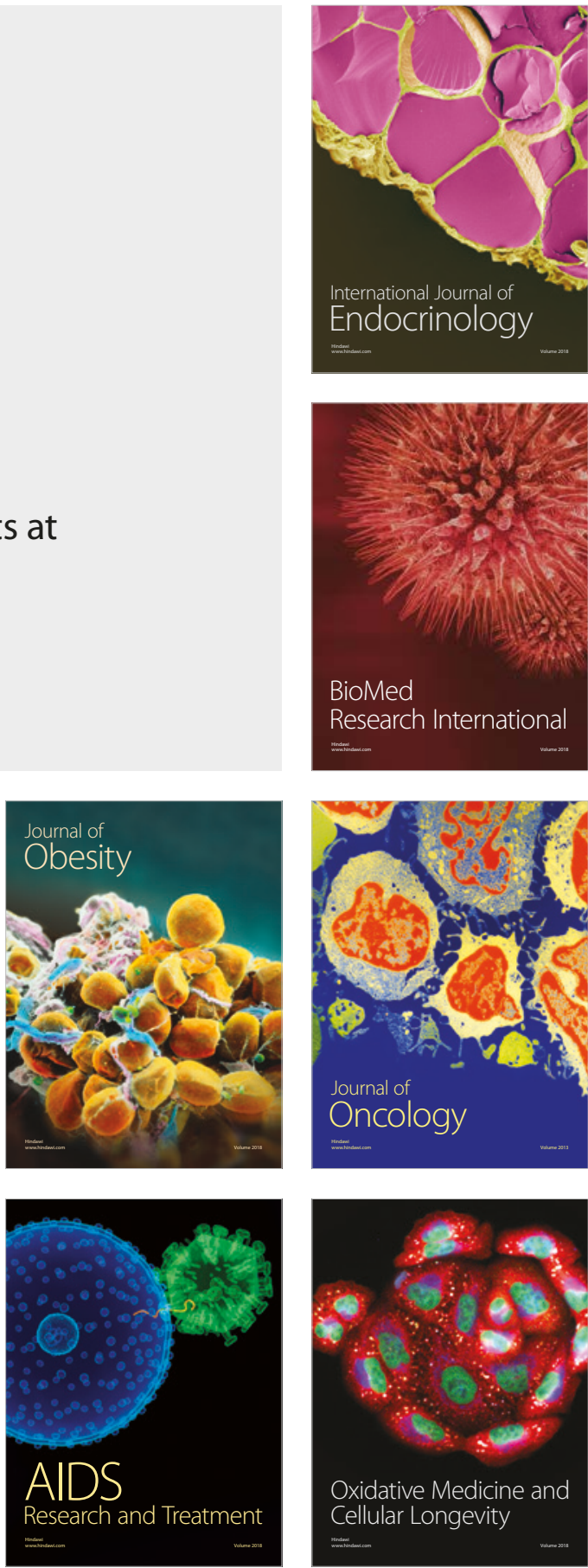